Supporting information for:

\title{
Synthesis and Characterization of Fluorescent Acenequinones as Dyes for Guest-Host Liquid Crystal Displays
}

\author{
Zhihua Chen, Timothy M. Swager* \\ Department of Chemistry, Massachusetts Institute of Technology, \\ Cambridge, Massachusetts 02139 \\ tswager@mit.edu
}

Details of experimental procedures:

NMR spectra:

page $S 1-S 8$

page $S 9-S 22$

General: NMR $\left({ }^{1} \mathrm{H},{ }^{13} \mathrm{C},{ }^{19} \mathrm{~F}\right)$ spectra were recorded on Varian Mercury-300 MHz, Varian Inova-500 MHz or Bruker Advance-400 MHz spectrometers. The ${ }^{1} \mathrm{H}$ and ${ }^{13} \mathrm{C}$ chemical shifts are given in unit of $\delta(\mathrm{ppm})$ relative the tetramethylsilane (TMS) where $\delta(\mathrm{TMS})=0$, and referenced to the residual solvent. ${ }^{19} \mathrm{~F}$ NMR chemical shifts are reported in ppm relative to hexafluorobenzene $(\delta=-164.9 \mathrm{ppm})$. High-resolution mass spectra (HRMS) were obtained on a Bruker Daltonics APED II 3T FT-ICR-MS using electron impact ionization (EI) or electrospray ionization (ESI). Melting points were measured on a Mel-Temp II apparatus (Laboratory Devices Inc.) and were not corrected. UV-vis spectra were obtained from Hewllett-Packard 8452A diode array UV-visible spectrophotometer or Cary $50 \mathrm{UV} /$ Visible spectrometer. Fluorescence spectra were measured with a SPEX Fluorolog- $\tau 2$ fluorometer (model FL112, 450W xenon lamp). Fourier Transform infrared (FT-IR) spectra were measured on a Perkin-Elmer model 2000 FT-IR spectrophotometer using the Spectrum v. 2.00 software package.

Materials: Anhydrous tetrahydrofuran (THF) and toluene were purchased from Aldrich Chemical Co., Inc. Furan was distilled from $\mathrm{K}_{2} \mathrm{CO}_{3}$ prior to use. Starting materials, 2,3dibromo-6,7-dihydroxynaphthalene $(\mathbf{1})^{1}$ and 1,4 -anthraquinone $(\mathbf{6})^{2}$, were prepared following literature procedures. All other reagent-grade starting materials were purchased from Aldrich, Lancaster, or Alfa Aesar, and used without further purification. Silica gel (40-63 $\mu \mathrm{m})$ was 
obtained from SiliCycle. Liquid crystal test cells with $10 \mu \mathrm{m}$ gap and parallel rubbed polyimide coatings were purchased from E.H.C. Co. Ltd, Tokyo, Japan. MLC-6884 is a liquid crystal mixture (negative dielectric anisotropy) for active matrix addressed ECB liquid crystal displays (LCDs) and it was purchased from EMD Chemicals Inc. E7 is a liquid crystal mixture with positive dielectric anisotropy and it was donated by Merck Chemicals Ltd. (UK). The composition of $\mathrm{E} 7$ is:

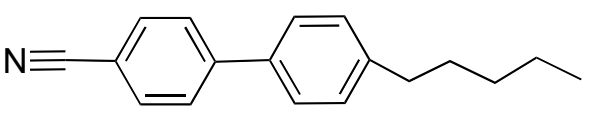

$51 \%$

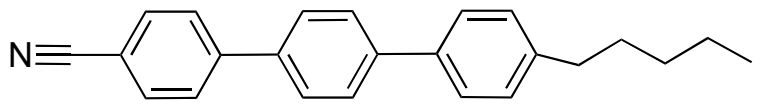

$8 \%$

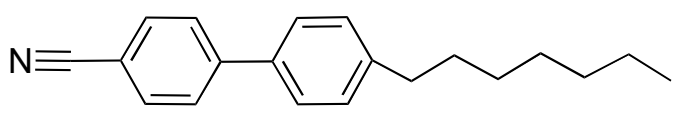

$25 \%$

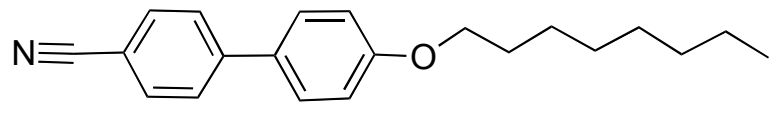

$16 \%$

\section{Syntheses:}

2,3-dibromo-6,7-bis(hexyloxy)naphthalene (2): In an oven-dried $100 \mathrm{~mL}$ round-bottom flask equipped with a stir bar were combined 1 ( $2.1 \mathrm{~g}, 6.6 \mathrm{mmol})$, 1-iodohexane $(3 \mathrm{~mL}, 20.3$ mmol), potassium carbonate $(9.8 \mathrm{~g}, 71.0 \mathrm{mmol}), 18$-crown-6 $(0.1 \mathrm{~g})$ and nitrogen-bubbled DMF $(50 \mathrm{~mL})$. The mixture was stirred under Ar at $85{ }^{\circ} \mathrm{C}$ for $5 \mathrm{~d}$. After cooling to room temperature, the reaction mixture was poured into $200 \mathrm{~mL}$ water and the product was extracted with $\mathrm{CH}_{2} \mathrm{Cl}_{2}$. The organic layer was washed by dilute $\mathrm{NH}_{4} \mathrm{Cl}$ aqueous solution and saturated $\mathrm{NaCl}$ aqueous solution, and then dried over $\mathrm{MgSO}_{4}$. Solvent was removed in vacuo and the residue was purified by column chromatography on silica gel with $\mathrm{CH}_{2} \mathrm{Cl}_{2}$ :hexane (1:5 up to $1: 3, \mathrm{v} / \mathrm{v}$ ), yielding a white solid as the product $(3.2 \mathrm{~g}, 87 \%)$. mp $66-67{ }^{\circ} \mathrm{C} .{ }^{1} \mathrm{H}$ NMR (300 MHz, $\left.\mathrm{CDCl}_{3}\right) 7.92(\mathrm{~s}, 2 \mathrm{H}), 6.96(\mathrm{~s}, 2 \mathrm{H}), 4.08(\mathrm{t}, 4 \mathrm{H}), 1.90(\mathrm{~m}, 4 \mathrm{H}), 1.52(\mathrm{~m}, 4 \mathrm{H}), 1.38$ (m, 8H), 0.93 (m, 6H). ${ }^{13} \mathrm{C}$ NMR (100 MHz, $\left.\mathrm{CDCl}_{3}\right)$ 150.6, 130.6, 129.4, 119.4, 106.3, 69.1, $31.8,29.1,25.9,22.8,14.2$. FT-IR $(\mathrm{KBr}) v / \mathrm{cm}^{-1}: 2956,2925,2852,1506,1466,1405,1381$, 1347, 1250, 1164, 1043, 994, 945, 881. HRMS (EI) calcd for $\mathrm{C}_{22} \mathrm{H}_{30} \mathrm{Br}_{2} \mathrm{O}_{2}\left(\mathrm{M}^{+}\right) 484.0608$, found 484.0608 .

1,4-epoxy-6,7-bis(hexyloxy)-1,4-dihydroanthracene (3): Under Ar, a stirred mixture of 2 $(2.5 \mathrm{~g}, 5.1 \mathrm{mmol})$, furan $(25 \mathrm{~mL})$ and anhydrous THF $(80 \mathrm{~mL})$ was cooled by an ice-water bath. A solution of phenyllithium $(\mathrm{PhLi})$ in cyclohexane/ether $(6 \mathrm{~mL}, 1.5-1.7 \mathrm{M})$ was then 
added dropwise over a course of $4 \mathrm{~h}$. After the addition of $\mathrm{PhLi}$, the mixture was stirred at 0 ${ }^{\circ} \mathrm{C}$ for an additional $2 \mathrm{~h}$, and then allowed to warm to room temperature slowly and stirred overnight. Methanol $(4 \mathrm{~mL})$ was added slowly to quench the reaction. The reaction mixture was poured into water and the product was extracted by $\mathrm{CH}_{2} \mathrm{Cl}_{2}$. The organic layer was washed by saturated $\mathrm{NaCl}$ aqueous solution and dried over $\mathrm{MgSO}_{4}$. Solvent was removed in vacuo. Purification by column chromatography on silica gel with $\mathrm{CH}_{2} \mathrm{Cl}_{2}$ :hexane (2:1 up to $3: 1, \mathrm{v} / \mathrm{v})$ afforded the title compound as a white solid (1.8 g, 89\%). mp 102-103 ${ }^{\circ} \mathrm{C} .{ }^{1} \mathrm{H}$ NMR $\left(400 \mathrm{MHz}, \mathrm{CDCl}_{3}\right) 7.46(\mathrm{~s}, 2 \mathrm{H}), 7.07(\mathrm{~s}, 2 \mathrm{H}), 6.97(\mathrm{~s}, 2 \mathrm{H}), 5.78(\mathrm{~s}, 2 \mathrm{H}), 4.09(\mathrm{t}, 4 \mathrm{H}), 1.89(\mathrm{~m}$, $4 \mathrm{H}), 1.53(\mathrm{~m}, 4 \mathrm{H}), 1.38(\mathrm{~m}, 8 \mathrm{H}), 0.93(\mathrm{t}, 6 \mathrm{H}) .{ }^{13} \mathrm{C} \mathrm{NMR}\left(100 \mathrm{MHz}, \mathrm{CDCl}_{3}\right)$ 149.4, 142.9, 142.0, 127.0, 117.8, 109.4, 82.1, 69.1, 31.8, 29.3, 25.9, 22.8, 14.2. FT-IR (KBr) v/cm ${ }^{-1}: 2954$, 2929, 2856, 1617, 1507, 1453, 1384, 1251, 1153, 1068, 983, 866, 841. HRMS (EI) calcd for $\mathrm{C}_{26} \mathrm{H}_{34} \mathrm{O}_{3}\left(\mathrm{M}^{+}\right)$394.2503, found 394.2512 .

exo/endo-6,13-epoxy-5a,6,13,13a-tetrahydro-9,10-bis(hexyloxy)pentacene-5,14-dione (4): A mixture of 3 (0.44 g, $1.1 \mathrm{mmol})$, 3,6-di-2-pyridyl-1,2,4,5-tetrazine (DPT) (0.27 g, 1.1 $\mathrm{mmol}), 1,4$-naphthoquinone $(0.18 \mathrm{~g}, 1.1 \mathrm{mmol})$ and toluene $(50 \mathrm{~mL})$ was stirred at $100{ }^{\circ} \mathrm{C}$ under Ar for $4 \mathrm{~d}$. After cooling to room temperature, the reaction mixture was concentrated on a rotary evaporator. The residue was dissolved in $\mathrm{CH}_{2} \mathrm{Cl}_{2}$ and then washed in sequence with $\mathrm{HCl}$ aqueous solution (5\%), water and saturated $\mathrm{NaCl}$ aqueous solution. Solvent was removed in vacuo. Purification by column chromatography on silica gel with ethyl acetate:hexane (1:6 up to $1: 4, \mathrm{v} / \mathrm{v})$ afforded both endo $(0.12 \mathrm{~g})$ and exo product $(0.43 \mathrm{~g})$ as a slightly yellow solid (94\%). Exo: ${ }^{1} \mathrm{H}$ NMR (400 MHz, $\left.\mathrm{CDCl}_{3}\right) 8.15$ (dd, 2H), 7.77 (dd, 2H), 7.64 (s, 2H), 7.12 (s, 2H), $5.86(\mathrm{~s}, 2 \mathrm{H}), 4.10(\mathrm{t}, 4 \mathrm{H}), 3.12(\mathrm{~s}, 2 \mathrm{H}), 1.90(\mathrm{~m}, 4 \mathrm{H}), 1.54(\mathrm{~m}, 4 \mathrm{H}), 1.39(\mathrm{~m}, 8 \mathrm{H}), 0.94(\mathrm{t}$, $6 \mathrm{H}) .{ }^{13} \mathrm{C}$ NMR $\left(100 \mathrm{MHz}, \mathrm{CDCl}_{3}\right)$ 195.6, 149.8, 140.2, 135.6, 134.7, 128.4, 127.4, 116.9, 108.6, 85.4, 69.0, 53.1, 31.8, 29.2, 25.9, 22.8, 14.2. FT-IR (KBr) v/ $\mathrm{cm}^{-1}: 2956,2920,2856$, $1669,1589,1502,1460,1390,1296,1271,1248,1158,972,866,850,821$. HRMS (EI) calcd for $\mathrm{C}_{34} \mathrm{H}_{38} \mathrm{O}_{5}\left(\mathrm{M}^{+}\right)$526.2714, found 526.2708; Endo: ${ }^{1} \mathrm{H}$ NMR (400 MHz, $\left.\mathrm{CDCl}_{3}\right) 7.63$ (dd, 2H), 7.29 (dd, 2H), 7.27 (s, 2H), 6.84 (s, 2H), 5.93 (dd, 2H), 3.97 (t, 4H), 3.86 (dd, 2H), 1.82 (m, 4H), 1.47 (m, 4H), 1.34 (m, 8H), 0.90 (t, 6H). $\left.{ }^{13} \mathrm{C} \mathrm{NMR} \mathrm{(100} \mathrm{MHz,} \mathrm{CDCl}_{3}\right)$ 194.8, 149.4, 137.6, 134.1, 133.9, 128.2, 126.4, 118.5, 108.2, 82.9, 68.8, 50.9, 31.7, 29.1, 25.8, 22.7, 14.2. FT-IR (KBr) $v / \mathrm{cm}^{-1}: 2952,2930,2856,1678,1617,1594,1502,1454,1390,1300,1271$, 
1248, 1191, 1158, 1014, 985, 940, 895, 854. HRMS (EI) calcd for $\mathrm{C}_{34} \mathrm{H}_{38} \mathrm{O}_{5}\left(\mathrm{M}^{+}\right)$526.2714, found 526.2737 .

9,10-bis(hexyloxy)pentacene-5,14-dione (5): A mixture of 4 (0.31 g, 0.59 mmol), pyridinium $p$-toluenesulfonate (PPTS) $(1.48 \mathrm{~g}, 5.9 \mathrm{mmol})$ and acetic anhydride $(10 \mathrm{~mL})$ was stirred at $80{ }^{\circ} \mathrm{C}$ for $16 \mathrm{~h}$. After the reaction mixture was cooled to room temperature, the precipitate was collected by filtration, washed thoroughly with methanol and dried in vacuum, affording the title compound as a red/orange solid (0.23 g, 77\%). mp 219-220 ${ }^{\circ} \mathrm{C} .{ }^{1} \mathrm{H}$ NMR $\left(400 \mathrm{MHz}, \mathrm{CDCl}_{3}\right) 8.71(\mathrm{~s}, 2 \mathrm{H}), 8.30(\mathrm{dd}, 2 \mathrm{H}), 8.20(\mathrm{~s}, 2 \mathrm{H}), 7.74(\mathrm{dd}, 2 \mathrm{H}), 7.05(\mathrm{~s}, 2 \mathrm{H}), 4.10$ (t, 4H), $1.92(\mathrm{~m}, 4 \mathrm{H}), 1.56(\mathrm{~m}, 4 \mathrm{H}), 1.42(\mathrm{~m}, 8 \mathrm{H}), 0.96(\mathrm{t}, 6 \mathrm{H}) .{ }^{13} \mathrm{C} \mathrm{NMR}\left(100 \mathrm{MHz}, \mathrm{CDCl}_{3}\right)$ $182.9,151.6,134.9,133.9,131.2,130.8,130.5,127.8,127.5,127.2,105.9,68.9,31.8,29.1$, 26.0, 22.8, 14.3. FT-IR (KBr) v/cm $\mathrm{cm}^{-1}$ 2953, 2929, 2854, 1665, 1570, 1489, 1432, 1324, 1300, 1223, 1152. HRMS (EI) calcd for $\mathrm{C}_{34} \mathrm{H}_{36} \mathrm{O}_{4}\left(\mathrm{M}^{+}\right)$508.2608, found 508.2624.

exo/edo-7,14-epoxy-6a,7,13,13a-tetrahydro-10,11-bis(hexyloxy)hexacene-6,15-dione (8): This was prepared from $3(0.72 \mathrm{~g}, 1.82 \mathrm{mmol})$, DPT (0.44 g, $1.86 \mathrm{mmol})$, and 1,4anthraquinone $(0.39 \mathrm{~g}, 1.87 \mathrm{mmol})$ in toluene $(70 \mathrm{~mL})$ as the same manner as described for 4 , yielding 8 (0.80 g, 76\%) as a yellow solid. Exo: ${ }^{1} \mathrm{H}$ NMR $\left(300 \mathrm{MHz}, \mathrm{CDCl}_{3}\right) 8.73(\mathrm{~s}, 2 \mathrm{H})$, 8.09 (dd, 2H), $7.71(\mathrm{dd}, 2 \mathrm{H}), 7.69(\mathrm{~s}, 2 \mathrm{H}), 7.15$ (s, 2H), $5.94(\mathrm{~s}, 2 \mathrm{H}), 4.12(\mathrm{t}, 4 \mathrm{H}), 3.26(\mathrm{~s}, 2 \mathrm{H})$, $1.91(\mathrm{~m}, 4 \mathrm{H}), 1.54(\mathrm{~m}, 4 \mathrm{H}), 1.39(\mathrm{~m}, 8 \mathrm{H}), 0.94(\mathrm{~m}, 6 \mathrm{H}) .{ }^{13} \mathrm{C} \mathrm{NMR}\left(125 \mathrm{MHz}, \mathrm{CDCl}_{3}\right)$ 195.9, $149.9,140.4,135.5,131.4,130.3,129.8,129.7,128.5,116.9,108.7,85.9,69.1,53.6,31.8$, 29.3, 25.9, 22.8, 14.3. FT-IR (KBr) v/ $\mathrm{cm}^{-1}:$ 2954, 2925, 2856, 1677, 1614, 1507, 1456, 1390, $1295,1276,1251,1191,1153,1093,1021,872,851,803$. HRMS (ESI) calcd for $\mathrm{C}_{38} \mathrm{H}_{41} \mathrm{O}_{5}$ $\left(\mathrm{M}+\mathrm{H}^{+}\right)$577.2949, found 577.2939; Endo: ${ }^{1} \mathrm{H}$ NMR (400 MHz, $\left.\mathrm{CDCl}_{3}\right) 8.12$ (s, 2H), 7.57 (dd, 2H), 7.31 (dd, 2H), 7.27 (s, 2H), 6.66 (s, 2H), 5.99 (dd, 2H), $3.92(\mathrm{dd}, 2 \mathrm{H}), 3.74(\mathrm{~m}, 4 \mathrm{H}), 1.63$ $(\mathrm{m}, 4 \mathrm{H}), 1.30(\mathrm{~m}, 4 \mathrm{H}), 1.28(\mathrm{~m}, 8 \mathrm{H}), 0.84(\mathrm{t}, 6 \mathrm{H}) .{ }^{13} \mathrm{C} \mathrm{NMR}\left(125 \mathrm{MHz}, \mathrm{CDCl}_{3}\right)$ 194.5, 149.1, 137.8, 134.5, 130.0, 129.5, 129.0, 128.5, 127.9, 118.3, 107.9, 82.9, 68.4, 51.0, 31.5, 28.9, 25.6, 22.5, 14.0. FT-IR (KBr) v/cm ${ }^{-1}: 2954,2929,2853,1677,1617,1852,1507,1456,1390,1302$, 1264, 1198, 1156, 1090, 1037, 942, 870, 854. HRMS (ESI) calcd for $\mathrm{C}_{38} \mathrm{H}_{41} \mathrm{O}_{5}[\mathrm{M}+\mathrm{H}]^{+}$ 577.2949, found 577.2960. 
10,11-bis(hexyloxy)hexacene-6,15-dione (10): A mixture of 8 (0.31 g, $0.54 \mathrm{mmol}), p$ toluenesulfonic acid monohydrate $\left(p-\mathrm{TsOH}_{\mathrm{s}} \mathrm{H}_{2} \mathrm{O}\right)(60 \mathrm{mg})$ in toluene $(20 \mathrm{~mL})$ was stirred at $100{ }^{\circ} \mathrm{C}$ under Ar for $13 \mathrm{~h}$. After cooling to room temperature, most of solvent was removed in vacuo. The residue was dissolved in $\mathrm{CH}_{2} \mathrm{Cl}_{2}$ and the product was washed with $\mathrm{H}_{2} \mathrm{O}$ and saturated $\mathrm{NaCl}$ aqueous solution, dried over $\mathrm{MgSO}_{4}$, and concentrated on a rotary evaporator. Purification by column chromatography on silica gel with $\mathrm{CH}_{2} \mathrm{Cl}_{2}$ :hexane (2:1, slowly up to $5: 1, \mathrm{v} / \mathrm{v})$ afforded the title compound as a yellow/orange solid $(0.19 \mathrm{~g}, 63 \%)$. mp $235-236^{\circ} \mathrm{C}$. ${ }^{1} \mathrm{H} \mathrm{NMR}\left(400 \mathrm{MHz}, \mathrm{CDCl}_{3}\right) 8.84$ (s, 2H), 8.81 (s, 2H), 8.26 (s, 2H), 8.04 (dd, 2H), 7.64 (dd, 2H), $7.07(\mathrm{~s}, 2 \mathrm{H}), 4.09(\mathrm{t}, 4 \mathrm{H}), 1.91(\mathrm{~m}, 4 \mathrm{H}), 1.55(\mathrm{~m}, 4 \mathrm{H}), 1.41(\mathrm{~m}, 8 \mathrm{H}), 0.96(\mathrm{t}, 6 \mathrm{H}) .{ }^{13} \mathrm{C}$ NMR (125 MHz, $\left.\mathrm{CDCl}_{3}\right)$ 183.0, 151.7, 135.3, 131.3, 131.0, 130.8, 130.2, 129.7, 129.4, 128.7, 127.1, 105.9, 69.0, 31.8, 29.1, 26.0, 22.9, 14.3. FT-IR (KBr) v/ $\mathrm{cm}^{-1}: 2950,2925,2852,1673$, $1570,1490,1457,1429,1393,1308,1228,1201,1155,988,930$. HRMS (ESI) calcd for $\mathrm{C}_{38} \mathrm{H}_{38} \mathrm{O}_{4} \mathrm{Na}[\mathrm{M}+\mathrm{Na}]^{+}$581.2662, found 581.2686.

1,2,3,4-tetrafluoro-10,11-bis(hexyloxy)hexacene-6,15-dione (11): This was prepared from 3 (0.37 g, $0.94 \mathrm{mmol})$, DPT (0.22 g, $0.93 \mathrm{mmol}$ ), and 6,7,8,9-tetrafluoro-1,4-anthraquinone (7) $(0.26 \mathrm{~g}, 0.93 \mathrm{mmol})$ in toluene $(40 \mathrm{~mL})$ as the same manner as described for $\mathbf{8}$. The crude product 9 was directly used for the dehydration step as described for $\mathbf{5}$, employing PPTS (1.0 $\mathrm{g}, 4.0 \mathrm{mmol})$ and acetic anhydride $(15 \mathrm{~mL})$, to afford the title compound as a yellow solid (0.12 g, 20\% over two steps). mp 332-334 ${ }^{\circ} \mathrm{C} .{ }^{1} \mathrm{H}$ NMR (300 MHz, $\left.\mathrm{CDCl}_{3}\right) 8.78$ (s, 2H), 8.68 (s, 2H), 8.10 (s, 2H), $6.91(\mathrm{~s}, 2 \mathrm{H}), 4.07$ (t, 4H), $19.4(\mathrm{~m}, 4 \mathrm{H}), 1.57$ (m, 4H), $1.44(\mathrm{~m}, 8 \mathrm{H}), 0.98$ (t, 6H). ${ }^{19}$ F NMR (282 MHz, CDCl $)$ ) 144.5 (d), -151.1 (d). FT-IR (KBr) v/ $/ \mathrm{cm}^{-1}:$ 2952, 2933, 2856, 1680, 1667, 1573, 1514, 1491, 1468, 1429, 1361, 1309, 1264, 1222, 1092, 1009, 992. HRMS (EI) calcd for $\mathrm{C}_{38} \mathrm{H}_{34} \mathrm{~F}_{4} \mathrm{O}_{4}\left(\mathrm{M}^{+}\right)$630.2388, found 630.2378 .

1,2,3,4-tetrafluoro-5,8-dihydroxyanthraquinone (12): A mixture of $\mathrm{AlCl}_{3}(5.0 \mathrm{~g})$ and $\mathrm{NaCl}$ $(1.1 \mathrm{~g})$ was pulverized using a mortar and pestle under a nitrogen atmosphere. The mixture was then transferred into an over-dried $50 \mathrm{~mL}$ Schlenk flask under Ar, and heated to $180{ }^{\circ} \mathrm{C}$. An intimate mixture of 3,4,5,6-tetrafluorophthalic anhydride $(1.1 \mathrm{~g}, 4.8 \mathrm{mmol}), 1,4-$ dihydroxybenzene $(0.6 \mathrm{~g}, 5.4 \mathrm{mmol})$ and $\mathrm{AlCl}_{3}(2.6 \mathrm{~g})$ was added to above melt. The heating temperature was raised to $220{ }^{\circ} \mathrm{C}$ and held there for $1.5 \mathrm{~h}$. The hot mixture was poured over 
on crushed ices and $40 \mathrm{~mL}$ concentrated $\mathrm{HCl}$ aqueous solution was then added. The resulting red/purple suspension solution was filtered, affording a brown solid as the product (1.2 $\mathrm{g}$, 81\%). ${ }^{1} \mathrm{H}$ NMR (400 MHz, $\left.\left(\mathrm{CD}_{3}\right)_{2} \mathrm{CO}\right)$ 12.37(s, 2H), 7.45 (s, 2H). ${ }^{19} \mathrm{~F}$ NMR (282 MHz, $\left.\left(\mathrm{CD}_{3}\right)_{2} \mathrm{CO}\right)$-133.0 (m), -141.8 (m). HRMS calcd for $\mathrm{C}_{14} \mathrm{H}_{4} \mathrm{~F}_{4} \mathrm{O}_{4}\left(\mathrm{M}^{+}\right)$312.0040, found 312.0037 .

6,7,8,9-tetrafluoro-1,4-anthraquinone (7): Under Ar, sodium borohydride $\left(\mathrm{NaBH}_{4}\right)(0.65 \mathrm{~g})$ was added in portions to a stirred solution $12(1.0 \mathrm{~g}, 3.2 \mathrm{mmol})$ in methanol $(30 \mathrm{~mL})$, which was cooled by an ice-water bath. After the addition of $\mathrm{NaBH}_{4}$, the reaction mixture was refluxed for $24 \mathrm{~h}$. The reaction mixture was then cooled to room temperature and poured into water $(60 \mathrm{~mL})$. The resulting solution was acidified with concentrated $\mathrm{HCl}$ solution. The precipitate was colleted by filtration and dried in vacuum, affording the title compound as a dark/brown solid (0.67g, 75\%). ${ }^{1} \mathrm{H}$ NMR (300 MHz, $\left.\mathrm{CDCl}_{3}\right) 8.87(\mathrm{~m}, 2 \mathrm{H}), 7.16(\mathrm{~s}, 2 \mathrm{H}) .{ }^{19} \mathrm{~F}$ NMR (282 MHz, $\left.\mathrm{CDCl}_{3}\right)-145.3$ (d), -151.6 (d). HRMS (EI) calcd for $\mathrm{C}_{14} \mathrm{H}_{4} \mathrm{~F}_{4} \mathrm{O}_{2}\left(\mathrm{M}^{+}\right)$ 280.0142 , found 280.0147 .

\section{(exo/endo)/(endo/endo)-[6,17],[8,15]-diepoxy-6,6a,7a,8,15,15a,16a,17-octahydro-}

2,3,11,12-tetrahexyloxyheptacene-7,16-dione (13): This was prepared from 5 (0.47 g, 1.19 $\mathrm{mmol})$, DPT (0.28 g, $1.18 \mathrm{mmol})$, and 1,4-benzoquinone (61 $\mathrm{mg}, 0.59 \mathrm{mmol})$ in toluene (50 $\mathrm{mL})$ as the same manner as described for $\mathbf{4}$, yielding both endo/endo product $(0.22 \mathrm{~g})$ and exo/endo product $(0.14 \mathrm{~g})$ as a white solid (totally $71 \%)$. The endo/endo product was not isolated. Exo/Exo: ${ }^{1} \mathrm{H}$ NMR (300 MHz, $\left.\mathrm{CDCl}_{3}\right) 7.44$ (s, 4H), 7.08 (s, 4H), 5.52 (m, 4H), 4.10 $(\mathrm{t}, 8 \mathrm{H}), 2.43(\mathrm{~m} 4 \mathrm{H}), 1.91(\mathrm{~m}, 8 \mathrm{H}), 1.54(\mathrm{~m}, 8 \mathrm{H}), 1.39(\mathrm{~m}, 16 \mathrm{H}), 0.93(\mathrm{~m}, 12 \mathrm{H}) .{ }^{13} \mathrm{C}$ NMR $\left(100 \mathrm{~Hz}, \mathrm{CDCl}_{3}\right)$ 206.7, 150.1, 138.0, 128.5, 118.4, 108.5, 82.7, 69.0, 52.8, 31.7, 29.2, 25.9, 22.8, 14.2. FT-IR (KBr) $v / \mathrm{cm}^{-1}: 2952,2927,2859,1682,1617,1502,1457,1390,1293,1252$, 1158, 1043, 988, 937, 899, 854. HRMS (ESI) calcd for $\mathrm{C}_{54} \mathrm{H}_{68} \mathrm{O}_{8} \mathrm{Na}\left(\mathrm{M}+\mathrm{Na}^{+}\right)$867.4806, found 867.4796; Exo/Endo: ${ }^{1} \mathrm{H} \mathrm{NMR}\left(300 \mathrm{MHz}, \mathrm{CDCl}_{3}\right) 7.56$ (s, 2H), 7.46 (s, 2H), 7.06 (s, 2H), $7.05(\mathrm{~s}, 2 \mathrm{H}), 5.78(\mathrm{~m}, 2 \mathrm{H}), 5.67(\mathrm{~s}, 2 \mathrm{H}), 4.06(\mathrm{~m}, 8 \mathrm{H}), 3.93(\mathrm{~m}, 2 \mathrm{H}), 2.20(\mathrm{~s}, 2 \mathrm{H}), 1.86$ $(\mathrm{m}, 8 \mathrm{H}), 1.50(\mathrm{~m}, 8 \mathrm{H}), 1.36(\mathrm{~m}, 16 \mathrm{H}), 0.91(\mathrm{~m}, 12 \mathrm{H}) .{ }^{13} \mathrm{C} \mathrm{NMR}\left(100 \mathrm{MHz}, \mathrm{CDCl}_{3}\right) 207.4$, 149.9, 149.7, 139.4, 138.9, 128.4, 128.3, 119.3, 116.7, 108.5, 85.0, 81.4, 69.0, 68.9, 56.9, 53.0, 31.7, 29.2, 25.9, 22.8, 14.2. FT-IR (KBr) $v / \mathrm{cm}^{-1}: 2952$, 2930, 2856, 1704, 1617, 1508, 1454, 
$1390,1300,1252,1155,1001,924,873,850$. HRMS (ESI) calcd for $\mathrm{C}_{54} \mathrm{H}_{68} \mathrm{O}_{8} \mathrm{Na}[\mathrm{M}+\mathrm{Na}]^{+}$ 867.4806, found 867.4777.

2,3,11,12-tetrahexyloxyheptacene-7,16-dione (14): This was prepared as the same manner as described for 10, employing $13(0.18 \mathrm{~g}, 0.21 \mathrm{mmol}), p-\mathrm{TsOH} \cdot \mathrm{H}_{2} \mathrm{O}(0.15 \mathrm{~g}, 0.79 \mathrm{mmol})$, and toluene $(12 \mathrm{~mL})$. A yellow/orange solid was obtained as the product (36 $\mathrm{mg}, 21 \%)$. $\mathrm{mp}$ 232-234 ${ }^{\circ} \mathrm{C} .{ }^{1} \mathrm{H}$ NMR (400 MHz, $\left.\mathrm{CDCl}_{3}\right) 8.87$ (s, 4H), 8.27 (s, 4H), 7.10 (s, 4H), 4.13 (t, 8H), $1.93(\mathrm{~m}, 8 \mathrm{H}), 1.57(\mathrm{~m}, 8 \mathrm{H}), 1.41(\mathrm{~m}, 16 \mathrm{H}), 0.96(\mathrm{t}, 12 \mathrm{H}) .{ }^{13} \mathrm{C} \mathrm{NMR}\left(125 \mathrm{MHz}, \mathrm{CDCl}_{3}\right) 183.2$, 151.7, 131.3, 131.2, 130.6, 129.3, 127.1, 106.0, 69.1, 31.8, 29.2, 26.0, 22.9, 14.3. FT-IR (KBr) $v / \mathrm{cm}^{-1}: 2953,2928,2858,1670,1570,1490,1463,1426,1317,1210,1158$. HRMS (EI) calcd for $\mathrm{C}_{54} \mathrm{H}_{64} \mathrm{O}_{6}\left(\mathrm{M}^{+}\right)$808.4696, found 808.4706.

\section{Polarized UV-vis absorption and fluorescence measurement:}

A solution of acenequinone in MLC-6884 (0.1-0.5wt\%) was loaded into a LC test cell via capillary action. The test cell consists of two glass plates coated with transparent electrodes (Indium tin oxide) $(1 \mathrm{~cm} \times 1 \mathrm{~cm})$ and parallel rubbed polyimide thin films. The polarized UVvis absorption spectra were obtained by irradiating the cell with polarized lights parallel and perpendicular to the rubbing direction of the test cell. Polarized fluorescence measurements were carried out according to the procedure previously reported by Breen et al. ${ }^{3}$

\section{Reference:}

(1) Cammidege, A. N.; Chambrier, I.; Cook, M. J.; Garland, A. D.; Heeney, M. H.; Welford, K. J. Porph. and Phth. 1997, 1,77.

(2) Hua, D. H.; Tamura, M.; Huang, X.; Stephany, H. A.; Helfrich, B. A.; Perchellet, E. M.; Sperfslage, B. J.; Perchellet, J.-P.; Jiang, S.; Kyle, D. E.; Chiang, P. K. J. Org. Chem. 2002, 67, 2907.

(3) Breen, C. A.; Deng, T.; Breiner, T.; Thomas, E. L.; Swager, T. M. J. Am. Chem. Soc. 2003, $125,9942$.

(4) Gaussian 03, Revision C.02. M. J. Frisch, G. W. Trucks, H. B. Schlegel, G. E. Scuseria, M. A. Robb, J. R. Cheeseman, J. A. Montgomery, Jr., T. Vreven, K. N. Kudin, J. C. Burant, J. M. Millam, S. S. Iyengar, J. Tomasi, V. Barone, B. Mennucci, M. Cossi, G. Scalmani, N. 
Rega, G. A. Petersson, H. Nakatsuji, M. Hada, M. Ehara, K. Toyota, R. Fukuda, J. Hasegawa, M. Ishida, T. Nakajima, Y. Honda, O. Kitao, H. Nakai, M. Klene, X. Li, J. E. Knox, H. P.

Hratchian, J. B. Cross, C. Adamo, J. Jaramillo, R. Gomperts, R. E. Stratmann, O. Yazyev, A. J. Austin, R. Cammi, C. Pomelli, J. W. Ochterski, P. Y. Ayala, K. Morokuma, G. A. Voth, P. Salvador, J. J. Dannenberg, V. G. Zakrzewski, S. Dapprich, A. D. Daniels, M. C. Strain, O.

Farkas, D. K. Malick, A. D. Rabuck, K. Raghavachari, J. B. Foresman, J. V. Ortiz, Q. Cui, A. G. Baboul, S. Clifford, J. Cioslowski, B. B. Stefanov, G. Liu, A. Liashenko, P. Piskorz, I. Komaromi, R. L. Martin, D. J. Fox, T. Keith, M. A. Al-Laham, C. Y. Peng, A. Nanayakkara, M. Challacombe, P. M. W. Gill, B. Johnson, W. Chen, M. W. Wong, C. Gonzalez, and J. A. Pople, Gaussian, Inc., Wallingford CT, 2004. 
${ }^{1} \mathrm{H}$ Spectrum of $\mathbf{2}$<smiles>CCOc1cc2cc(OCC)c(Br)cc2cc1Br</smiles>

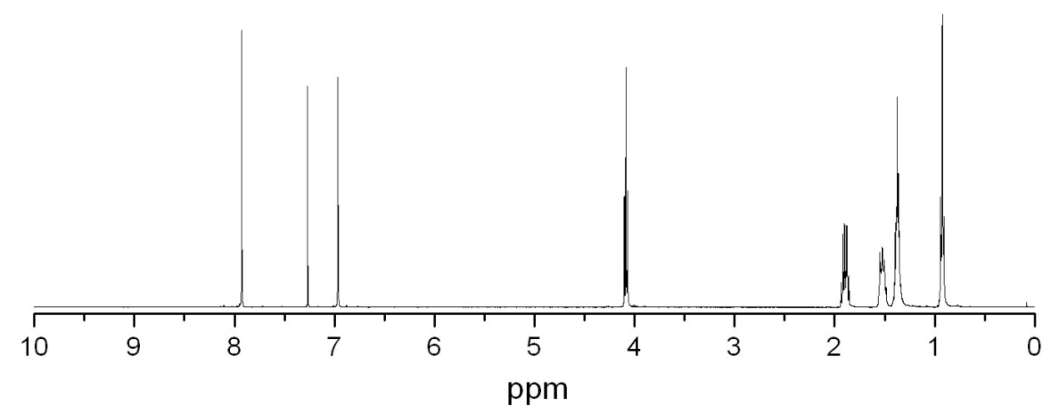

${ }^{13} \mathrm{C}$ Spectrum of 2

$\mathrm{C}_{6} \mathrm{H}_{13} \mathrm{O}$

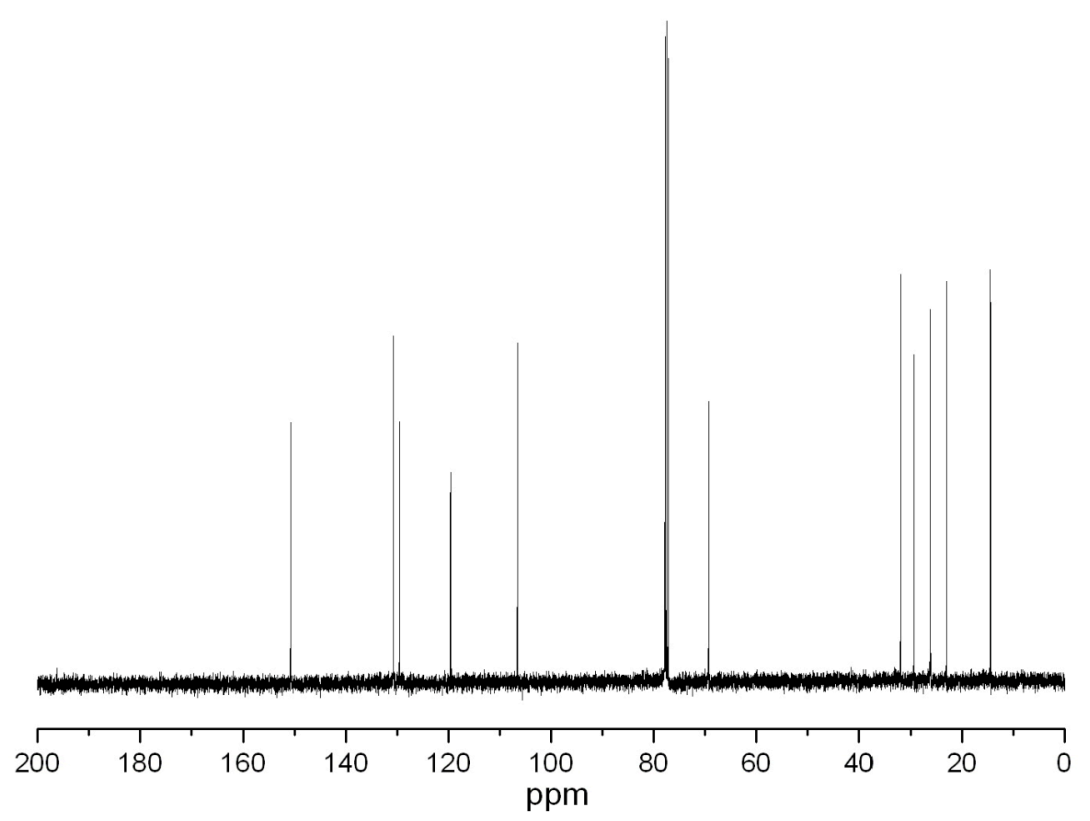


${ }^{1} \mathrm{H}$ Spectrum of $\mathbf{3}$

$\mathrm{C}_{6} \mathrm{H}_{13} \mathrm{O}$

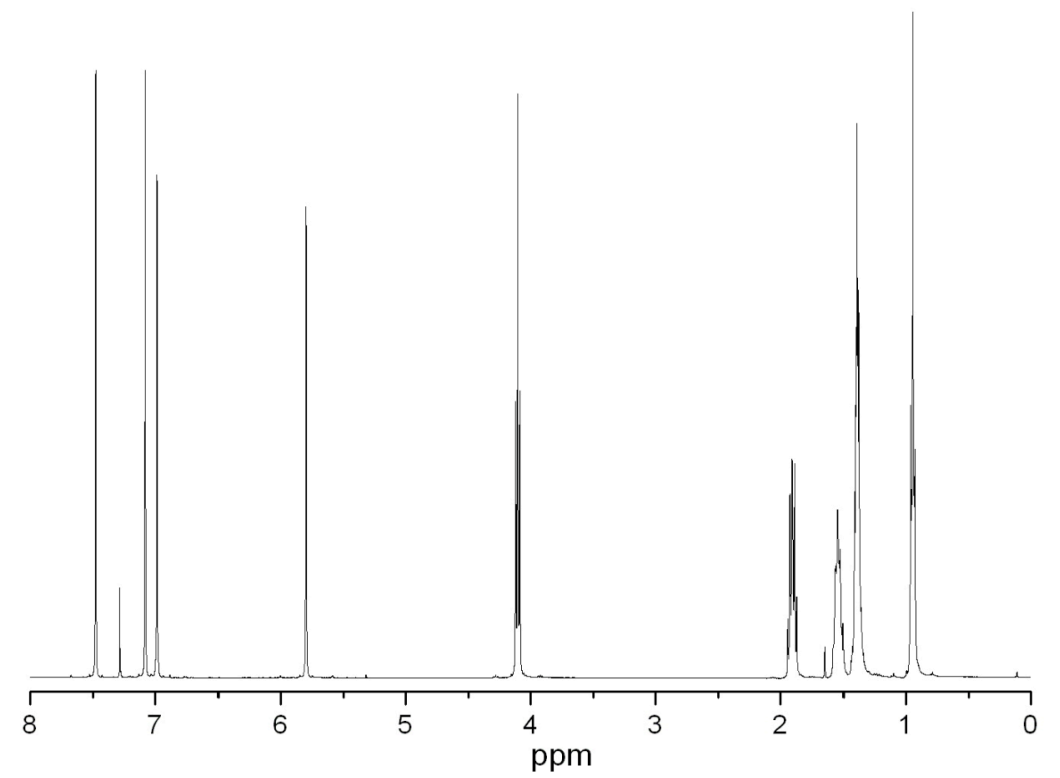

${ }^{13} \mathrm{C}$ Spectrum of 3
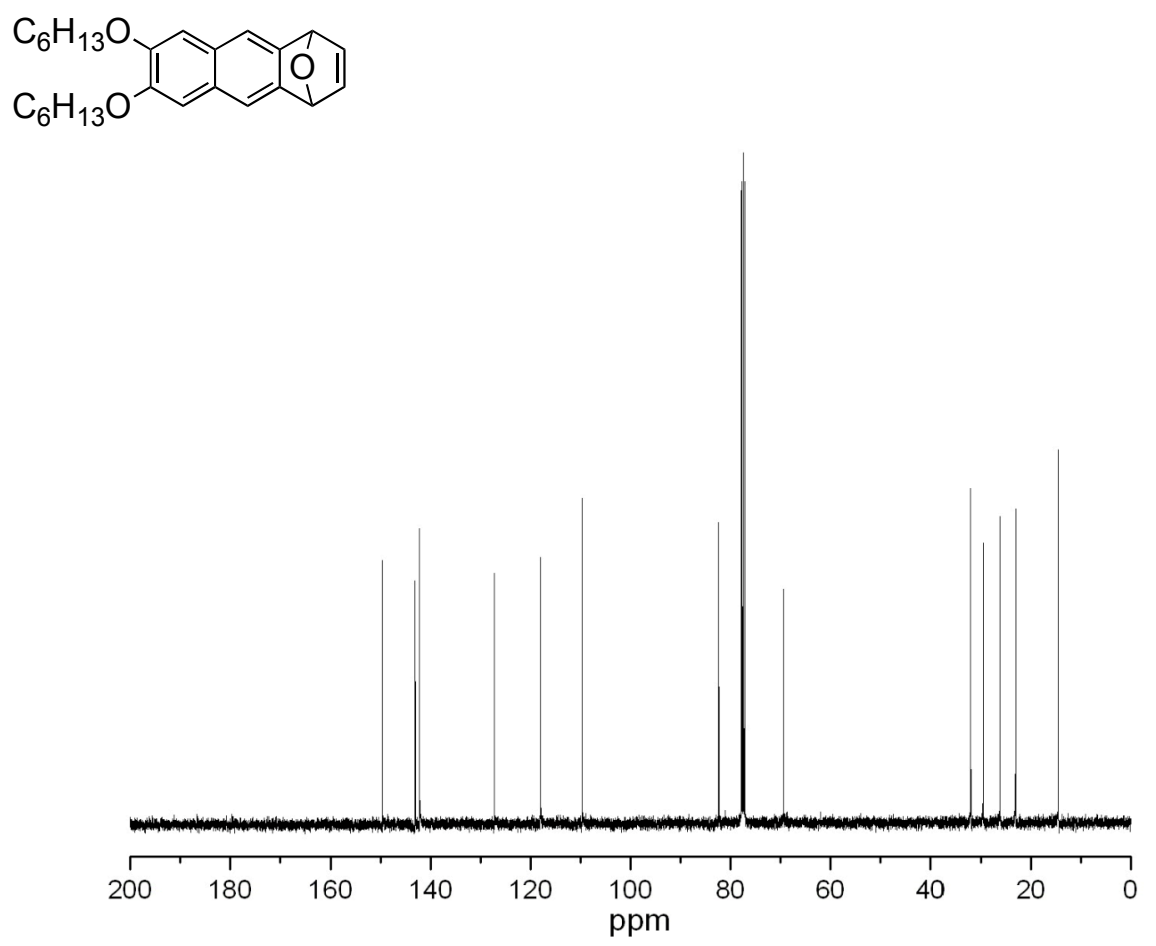
${ }^{1} \mathrm{H}$ Spectrum of 4 (exo)

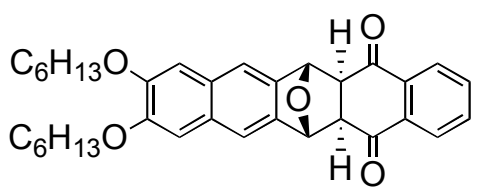

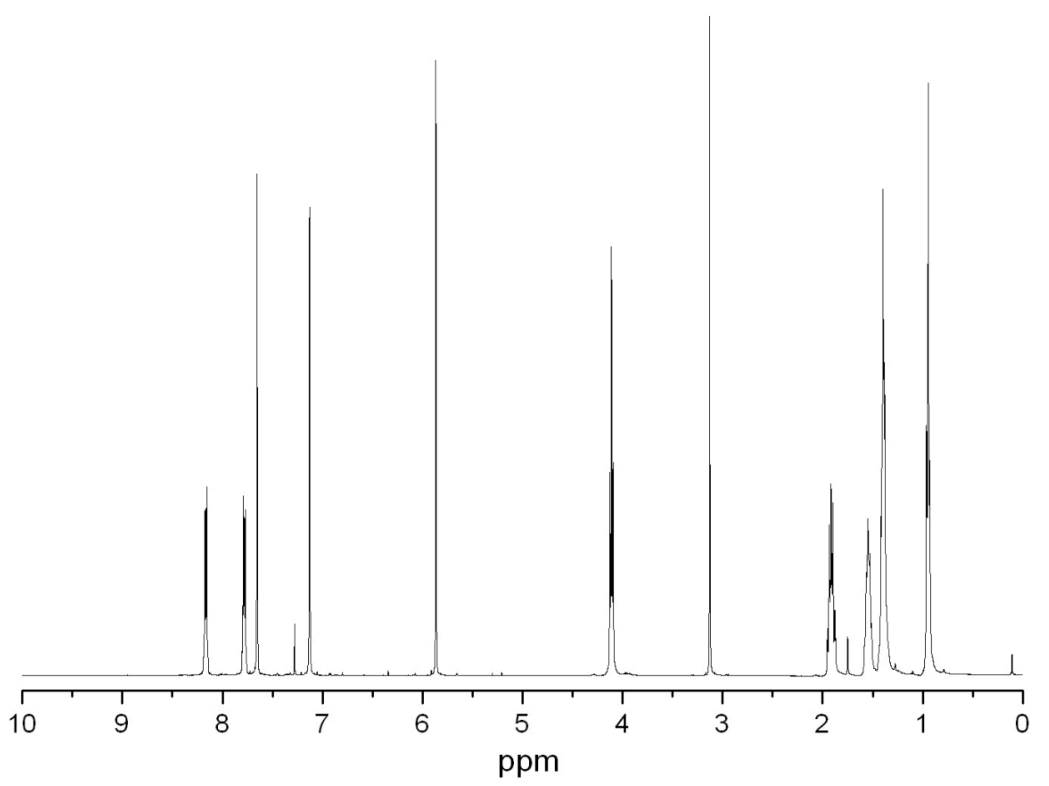

${ }^{13} \mathrm{C}$ Spectrum of 4 (exo)

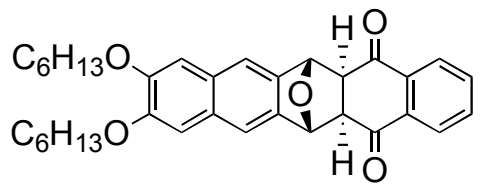

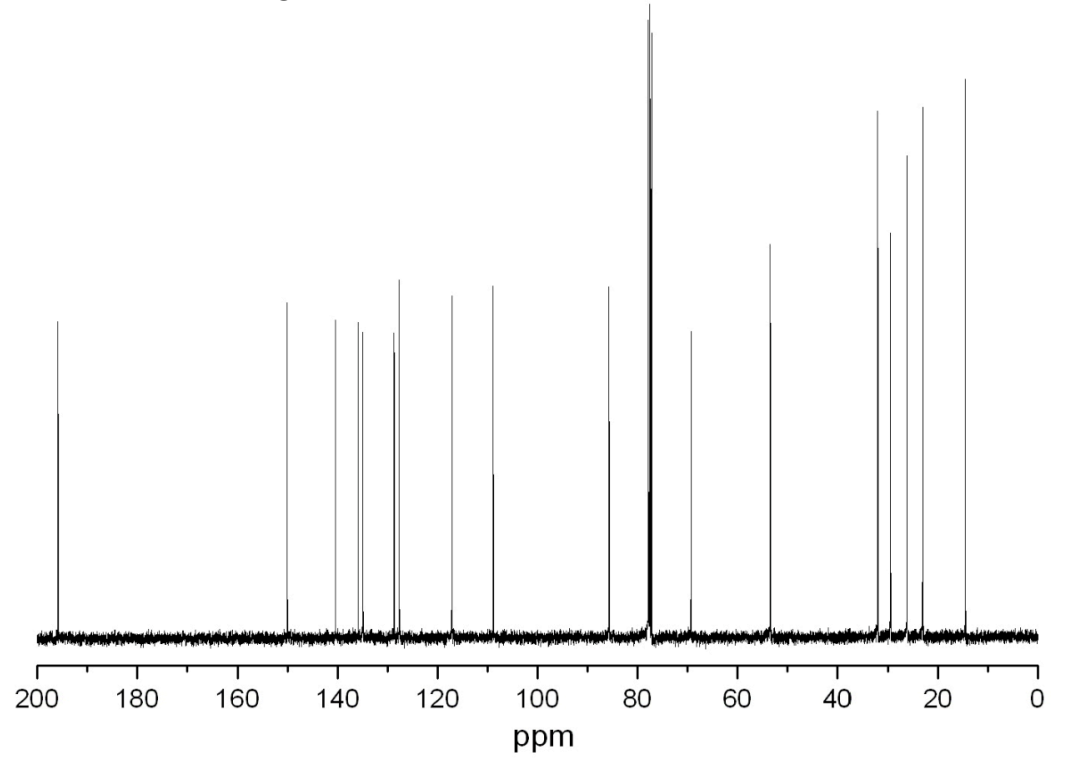


${ }^{1} \mathrm{H}$ Spectrum of 4 (endo)

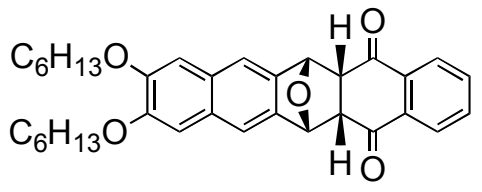

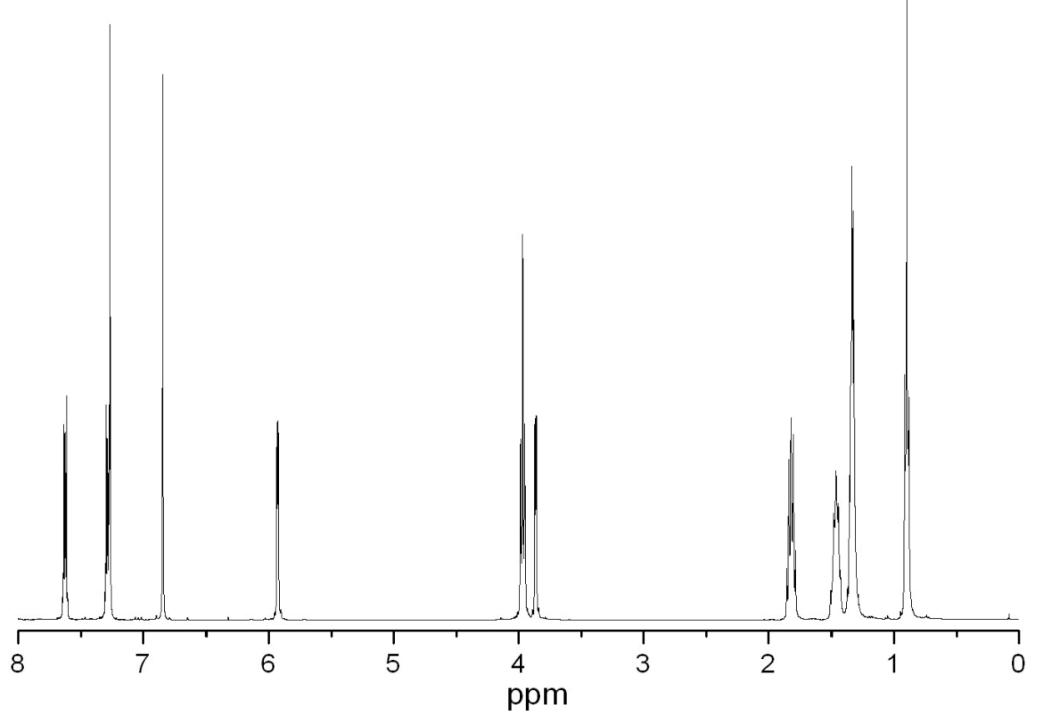

${ }^{13} \mathrm{C}$ Spectrum of 4 (endo)

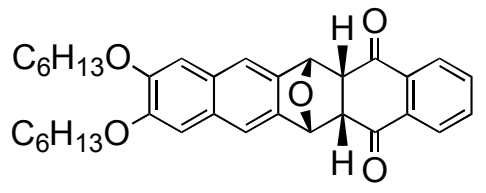

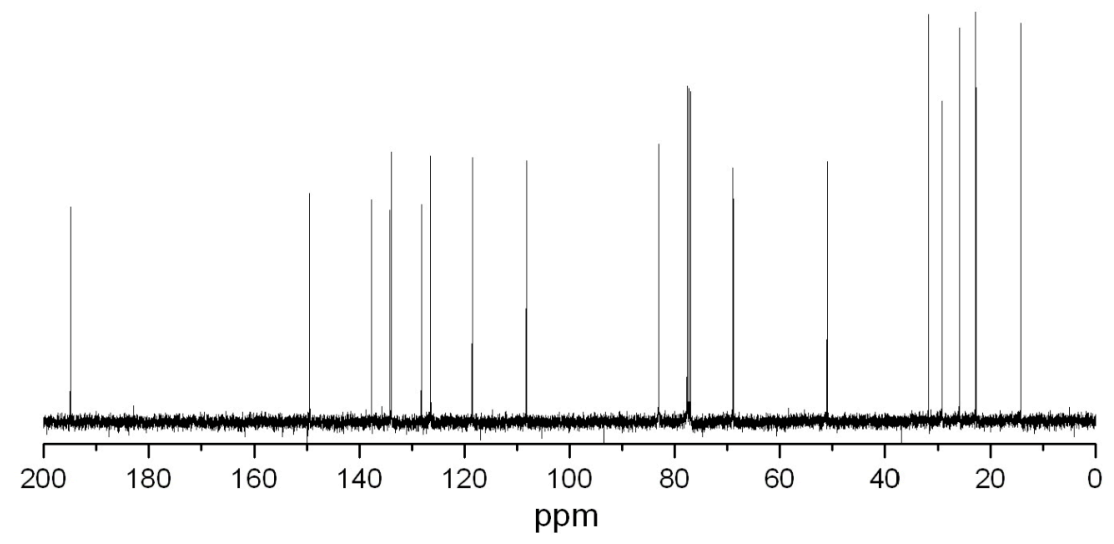


${ }^{1} \mathrm{H}$ Spectrum of $\mathbf{5}$
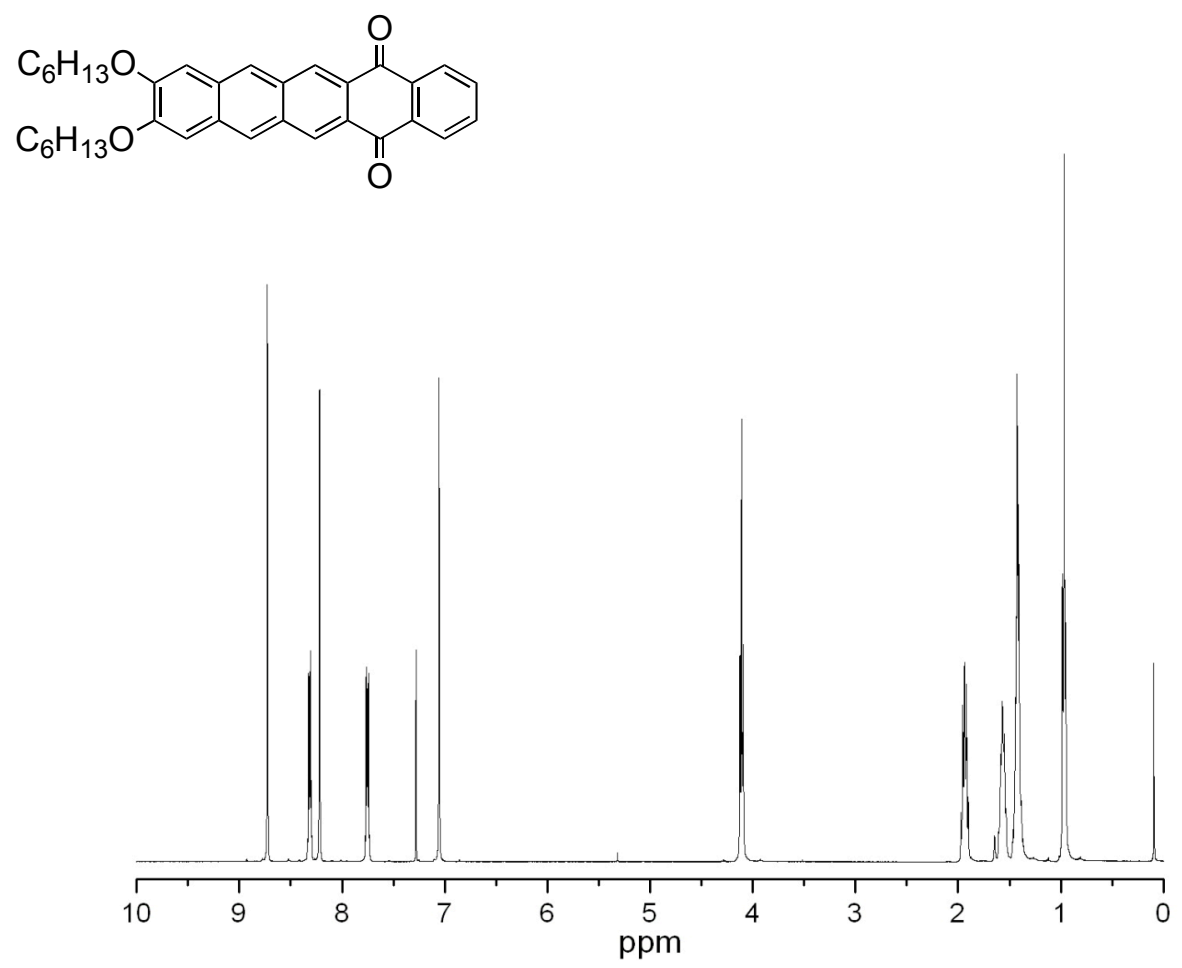

${ }^{13} \mathrm{C}$ Spectrum of $\mathbf{5}$
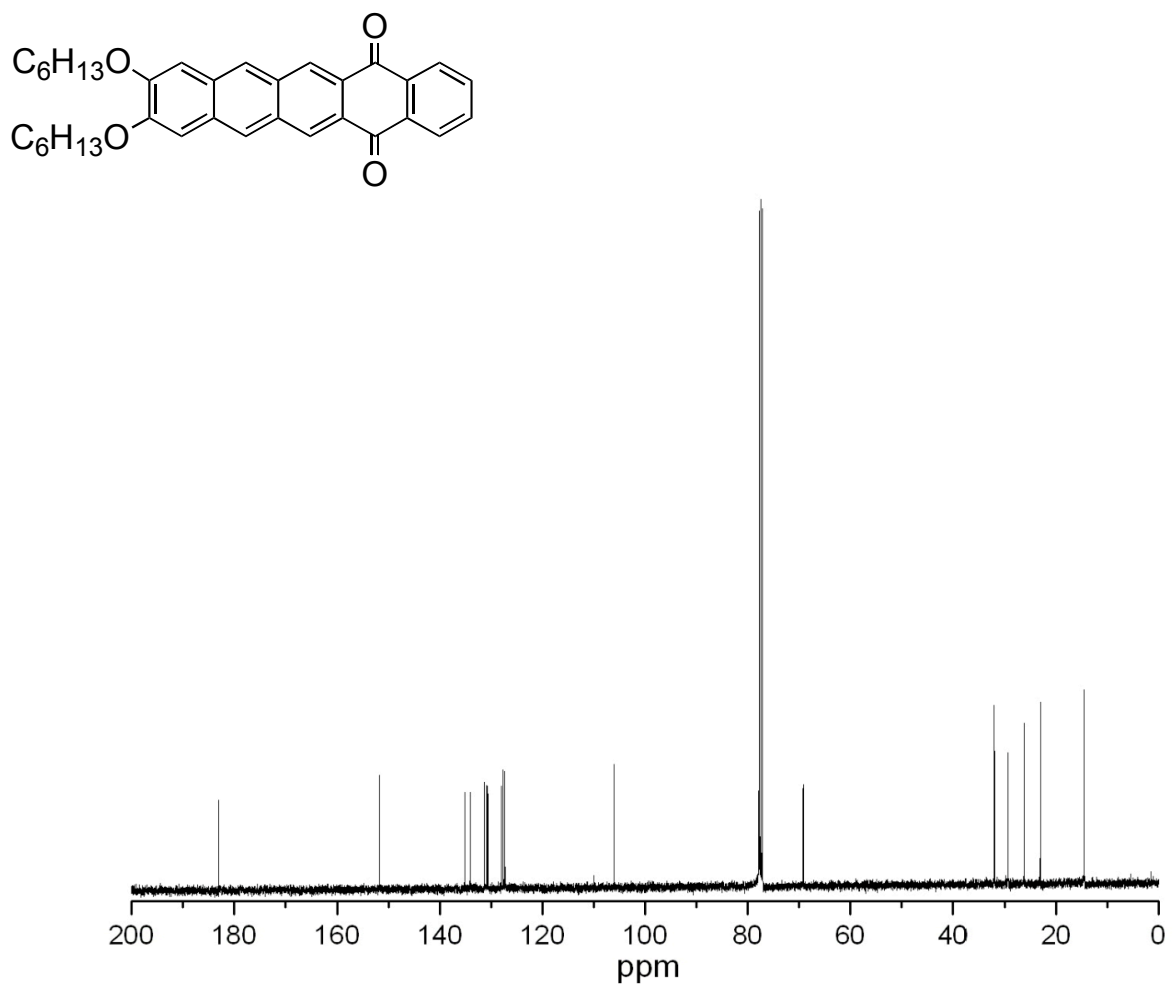

S13 
${ }^{1} \mathrm{H}$ Spectrum of 8 (exo)
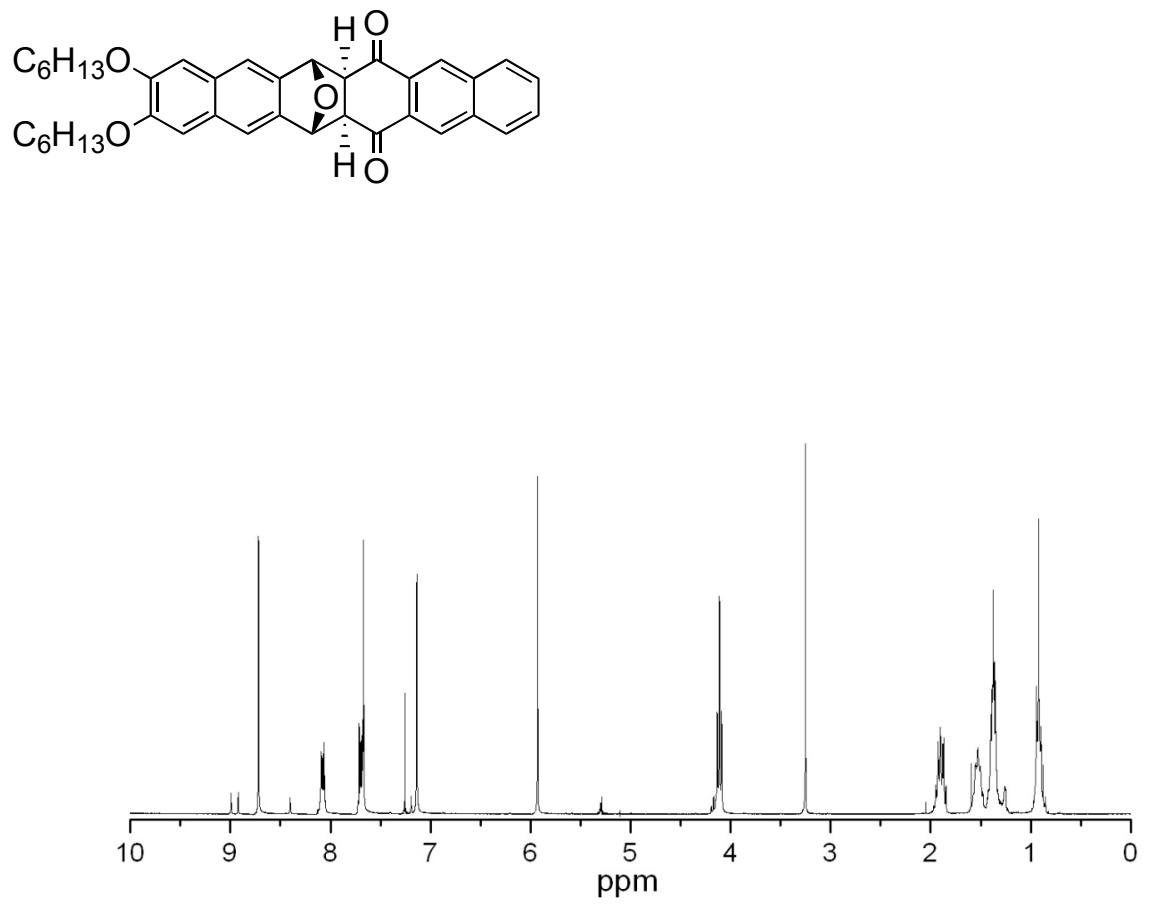

${ }^{13} \mathrm{C}$ Spectrum of 8 (exo)
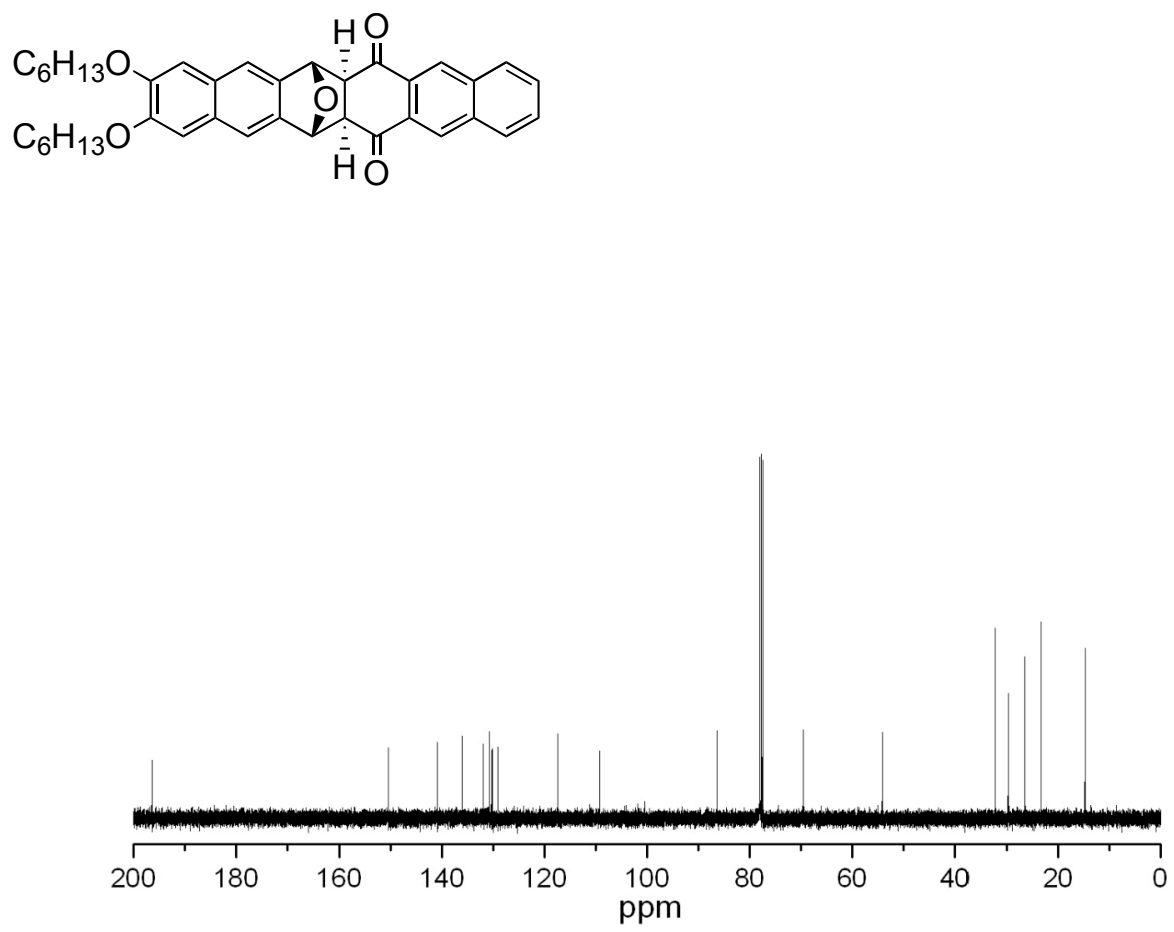

S14 
${ }^{1} \mathrm{H}$ Spectrum of 8 (endo)
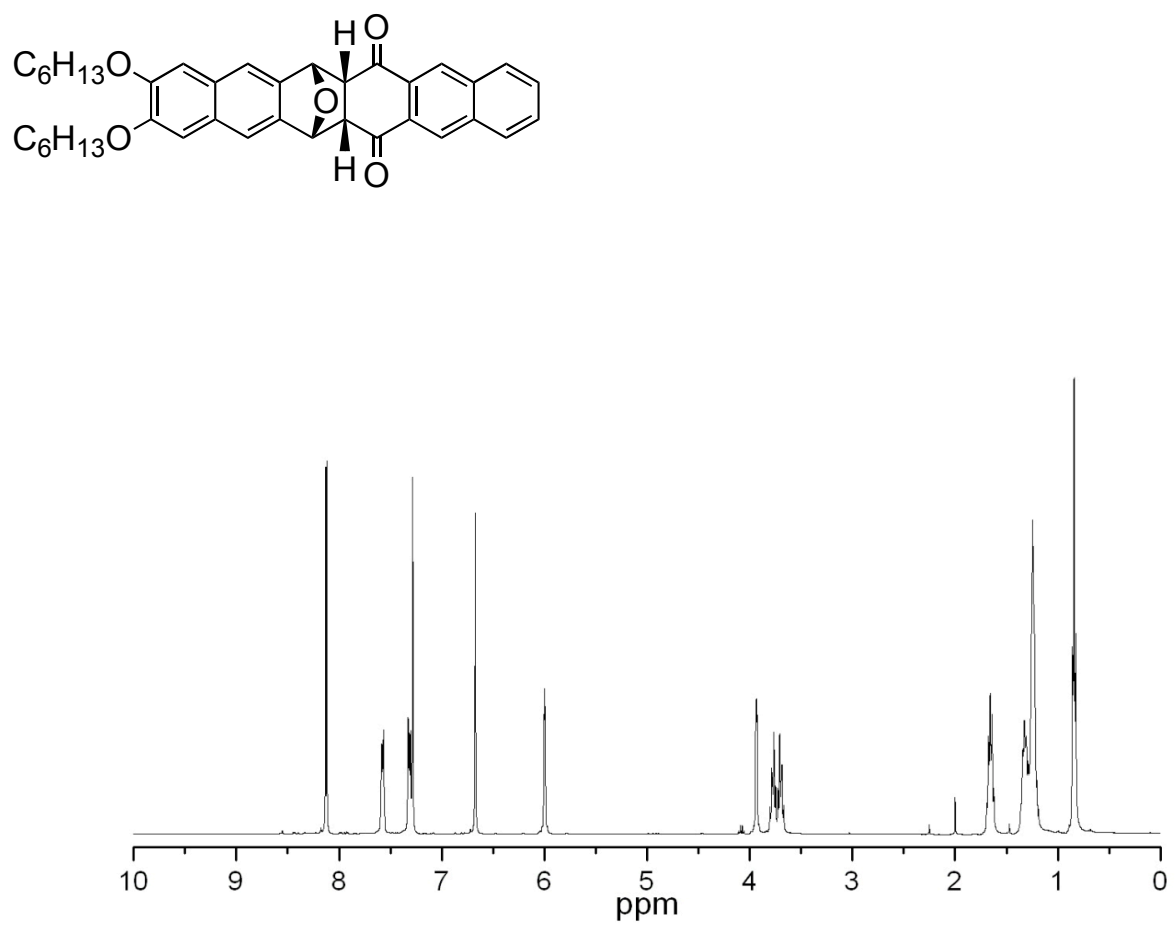

${ }^{13} \mathrm{C}$ Spectrum of 8 (endo)
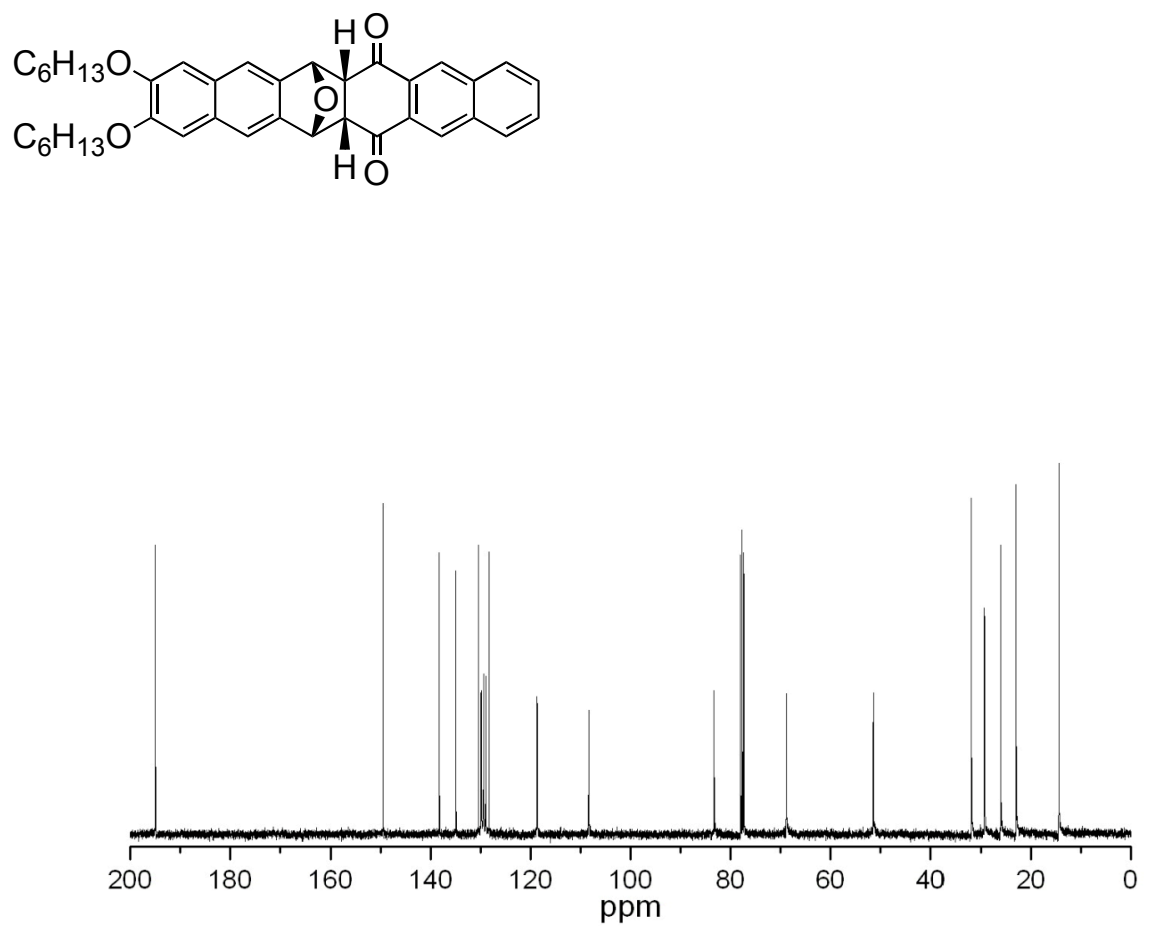

S15 


\section{${ }^{1} \mathrm{H}$ Spectrum of $\mathbf{1 0}$}<smiles>CCOc1cc2cc3cc4c(cc3cc2cc1OC)C(=O)c1cc2ccccc2cc1C4=O</smiles>

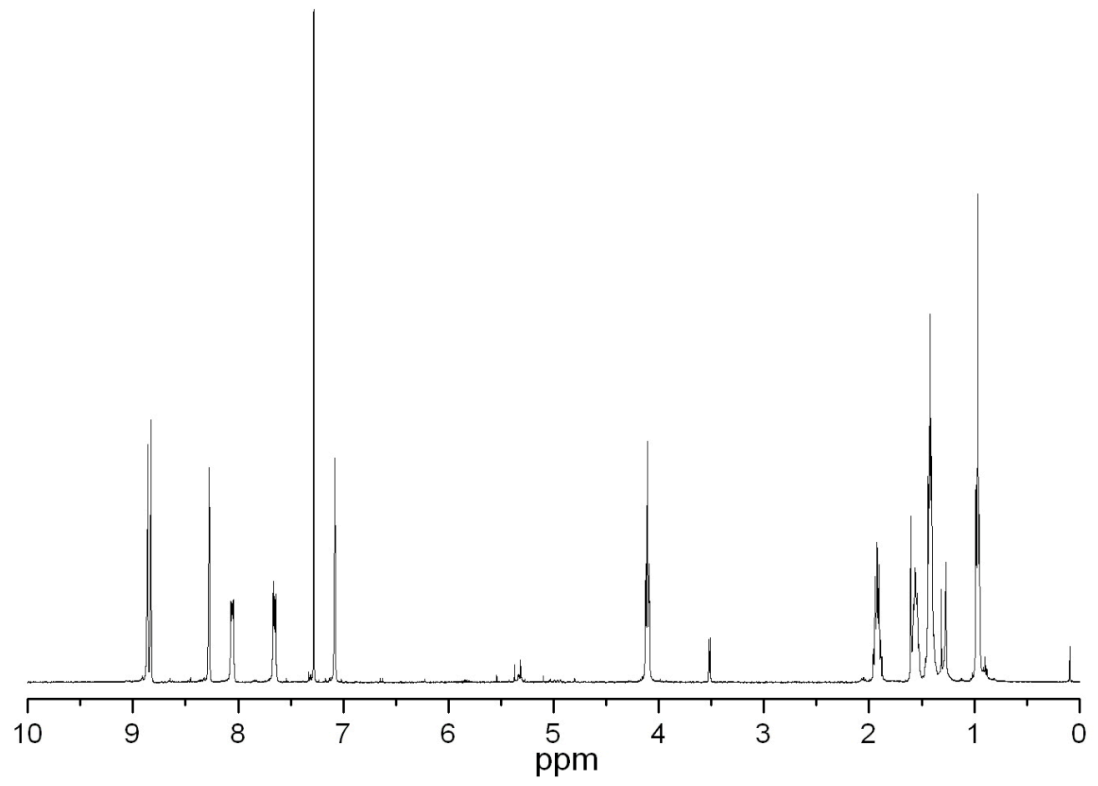

${ }^{13} \mathrm{C}$ Spectrum of $\mathbf{1 0}$<smiles></smiles>

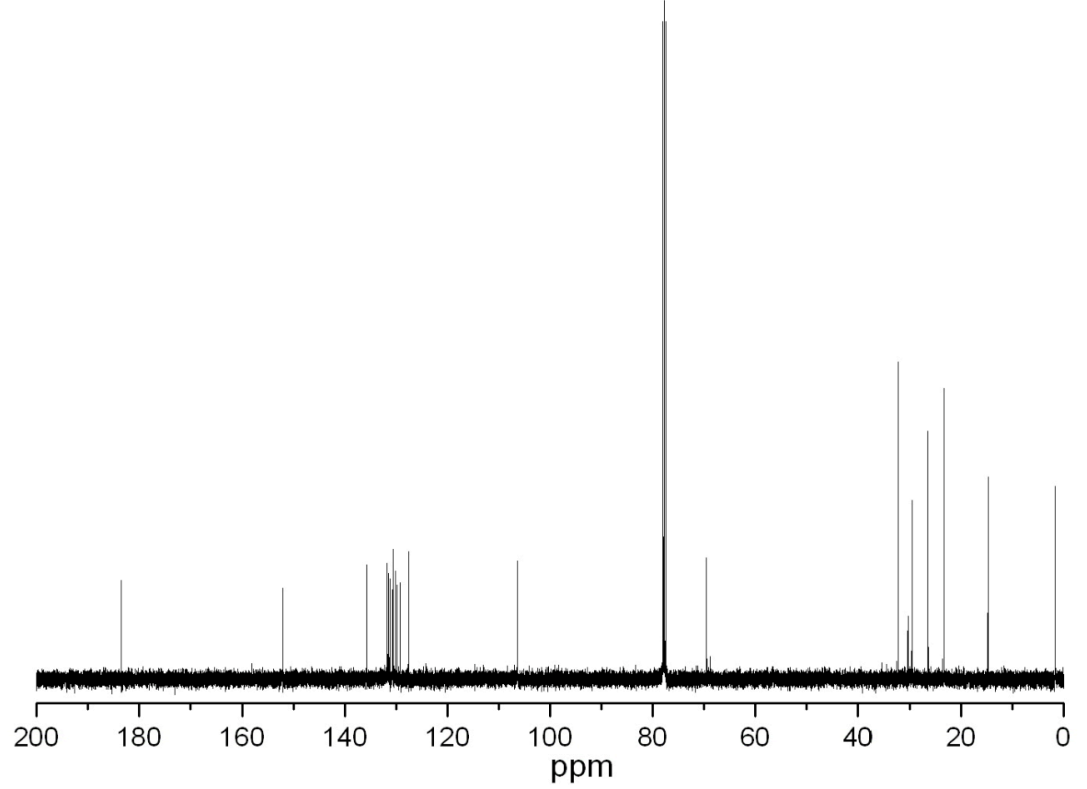


${ }^{1} \mathrm{H}$ Spectrum of $\mathbf{1 1}$

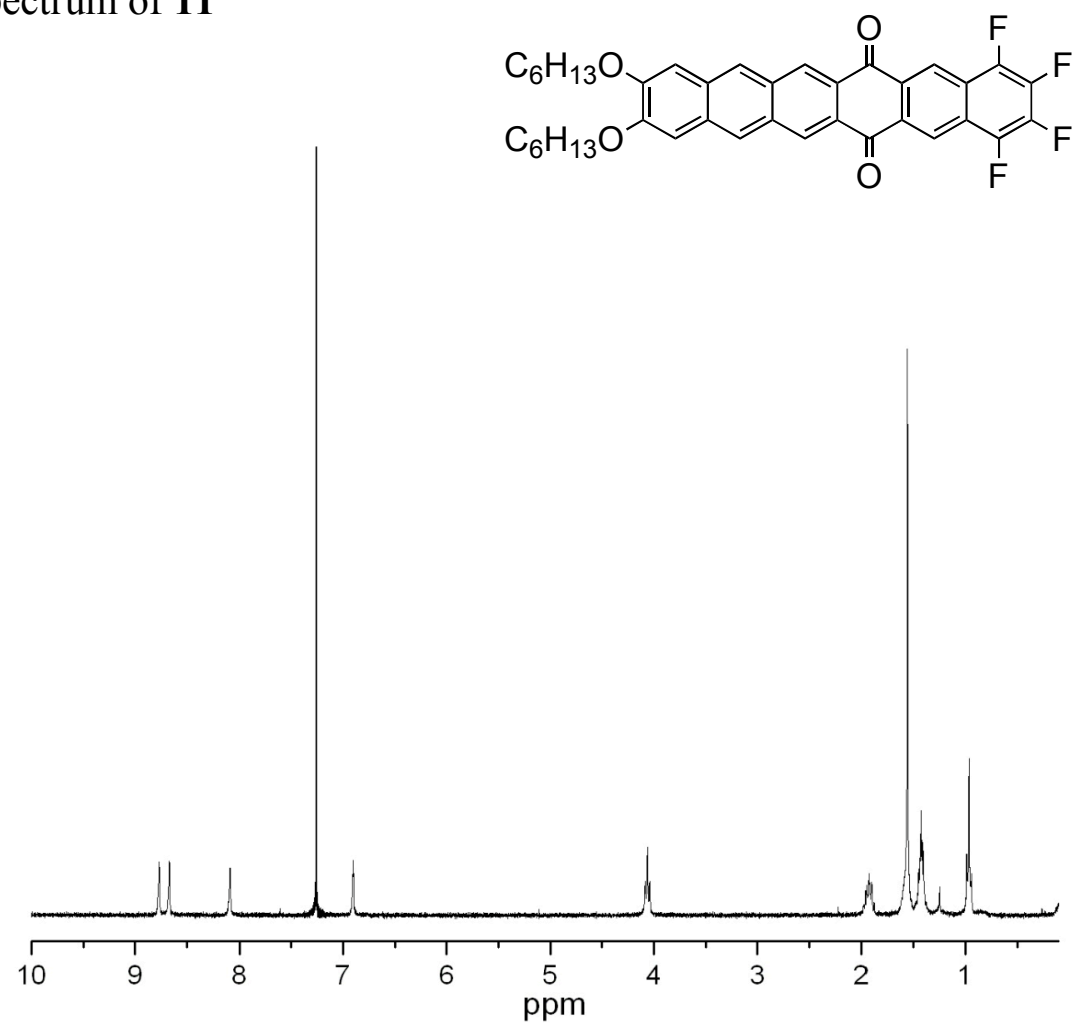

${ }^{19} \mathrm{~F}$ Spectrum of $\mathbf{1 1}$
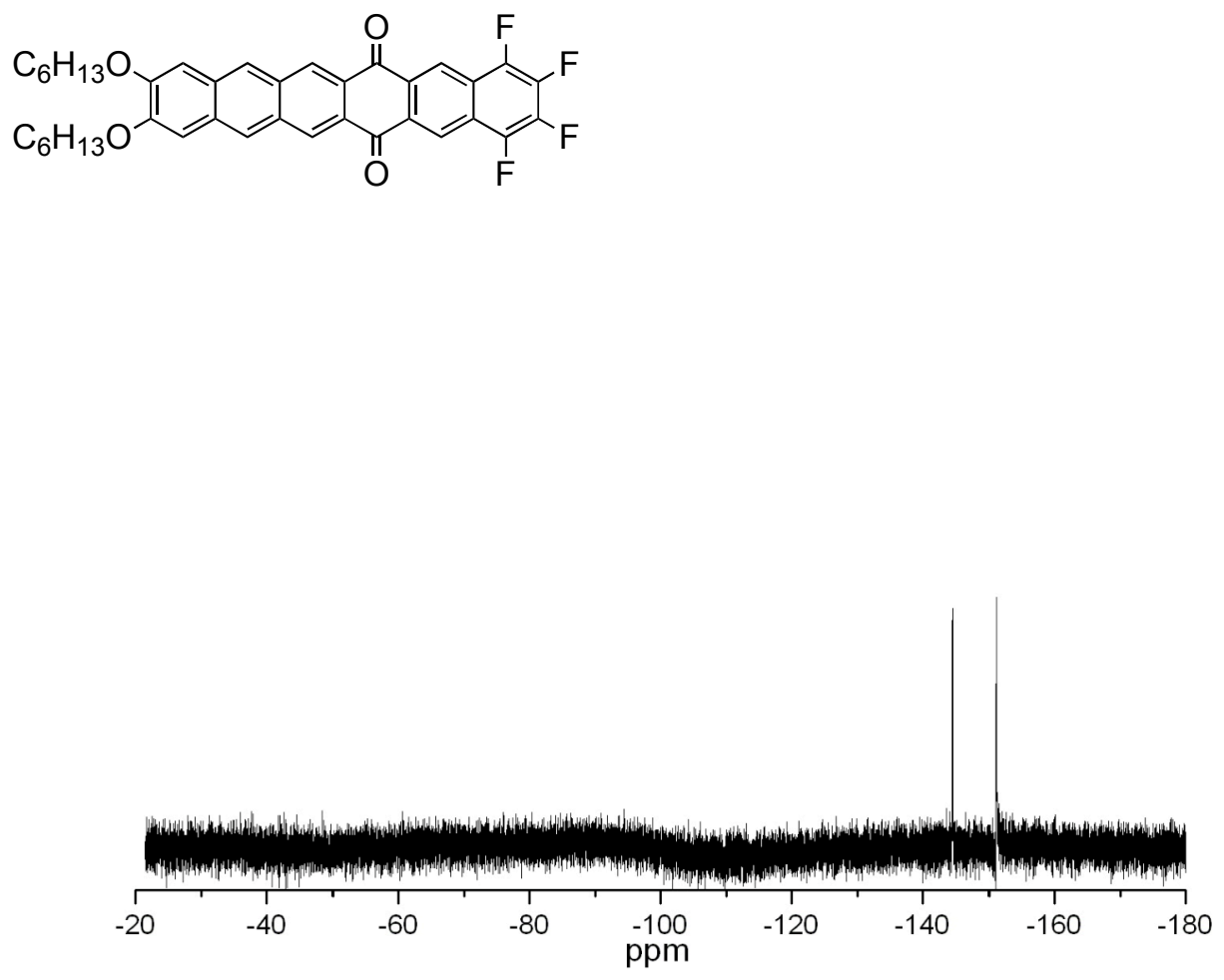

S17 


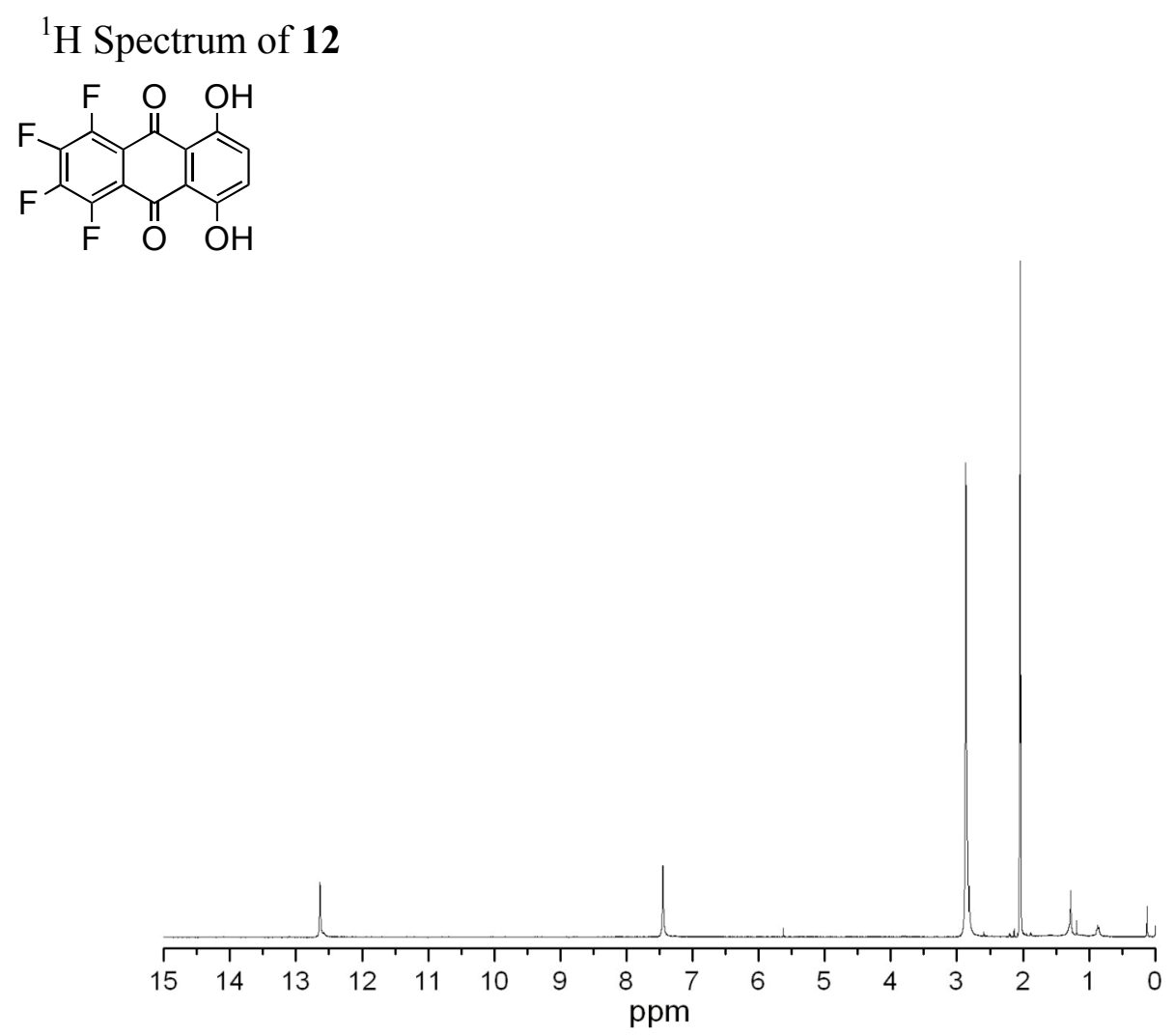

${ }^{19} \mathrm{~F}$ Spectrum of $\mathbf{1 2}$<smiles>O=C1c2c(O)ccc(O)c2C(=O)c2c(F)c(F)c(F)c(F)c21</smiles>

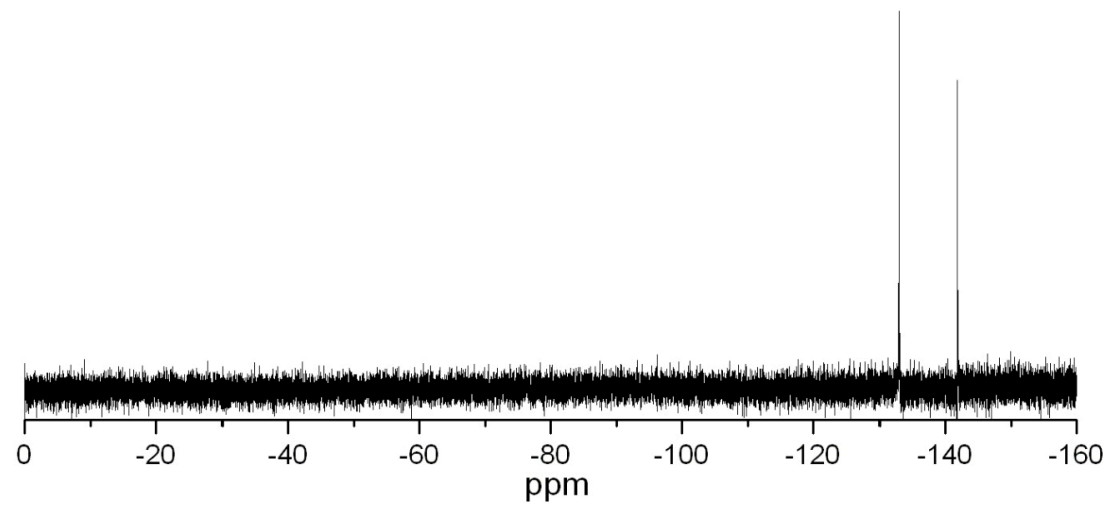




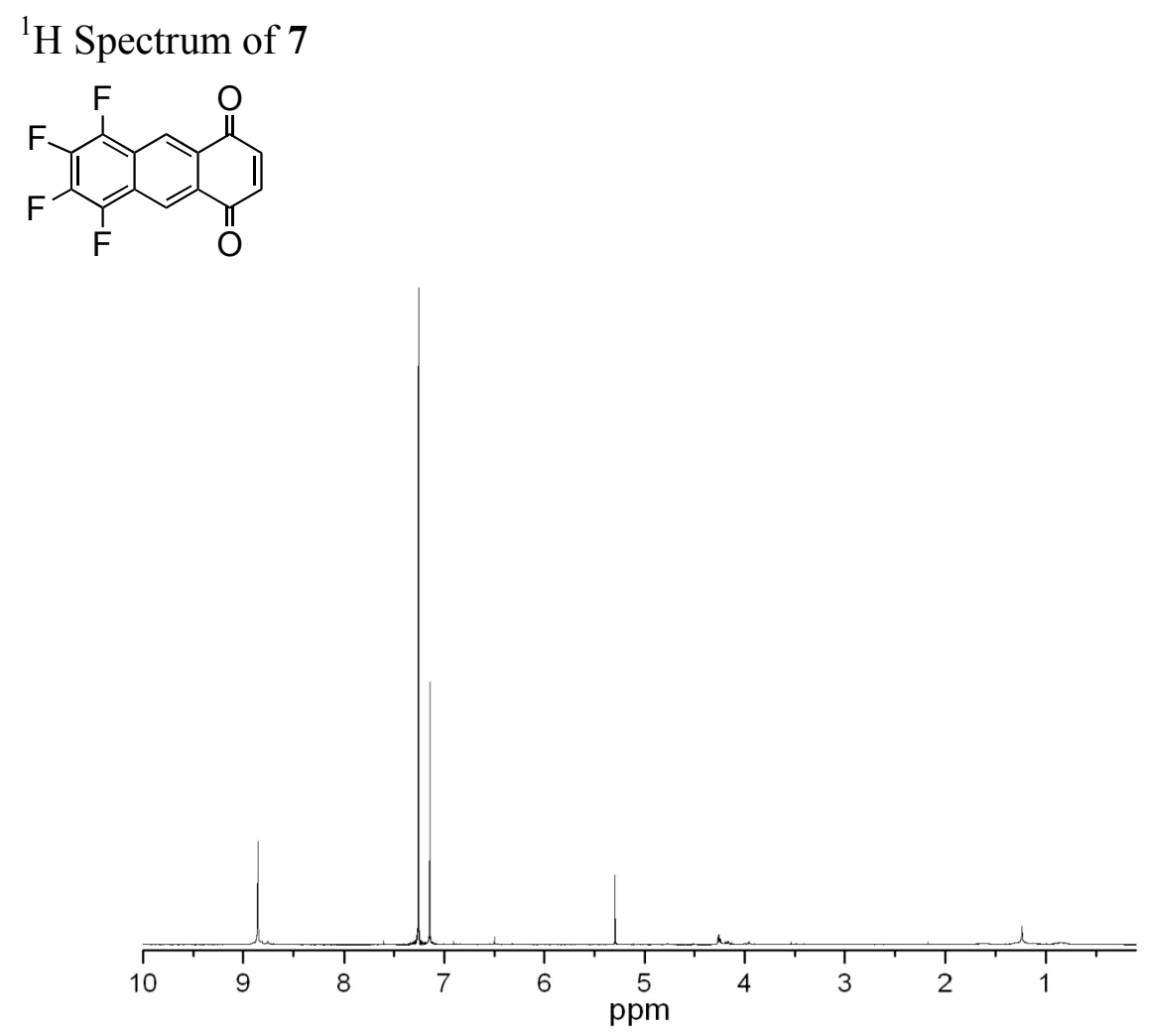

${ }^{19} \mathrm{~F}$ Spectrum of 7<smiles>O=C1C=CC(=O)c2cc3c(F)c(F)c(F)c(F)c3cc21</smiles>

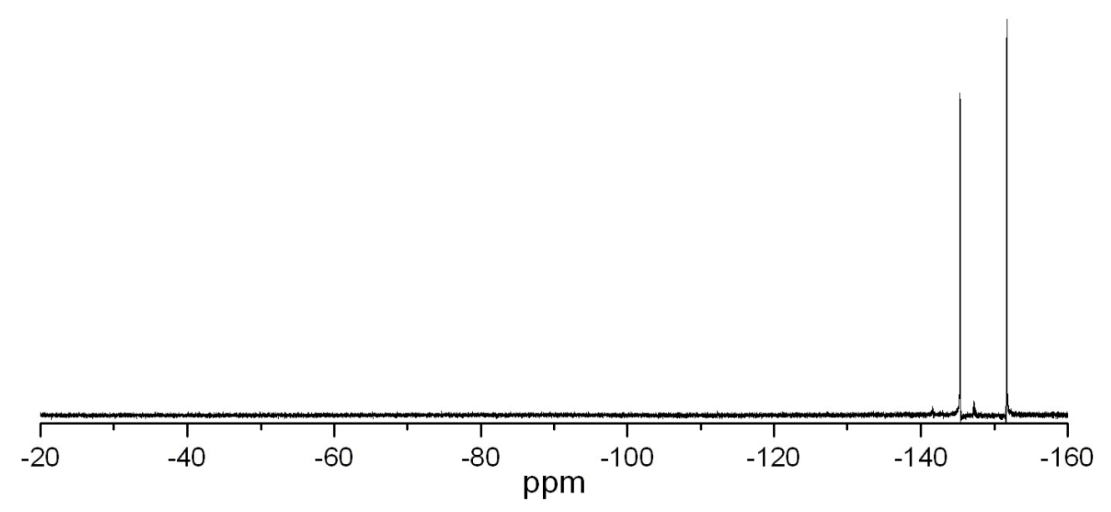


${ }^{1} \mathrm{H}$ Spectrum of $\mathbf{1 3}$ (exo/endo)

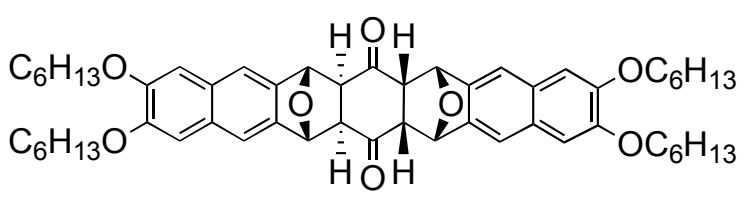

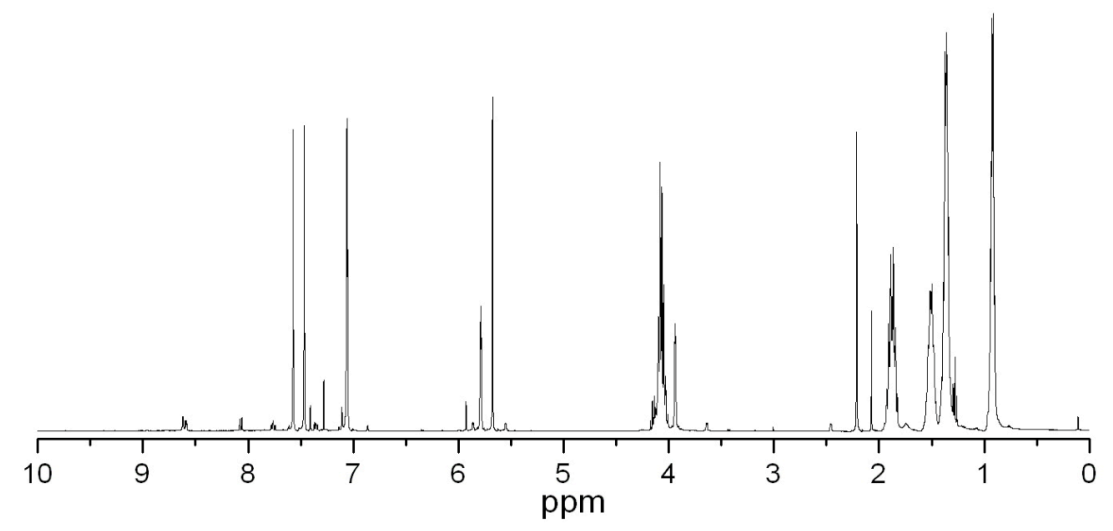

${ }^{13} \mathrm{C}$ Spectrum of 13 (exo/endo)
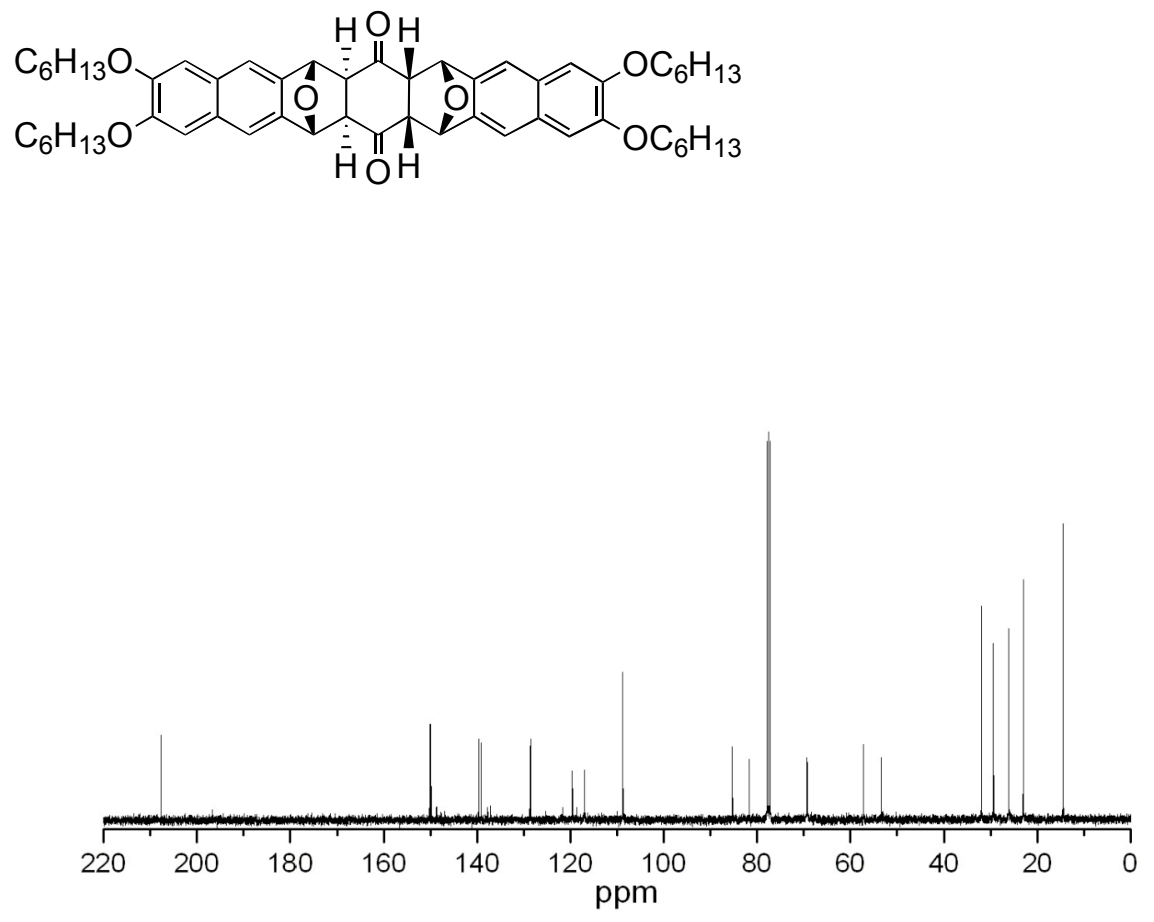
${ }^{1} \mathrm{H}$ Spectrum of 13 (exo/exo)

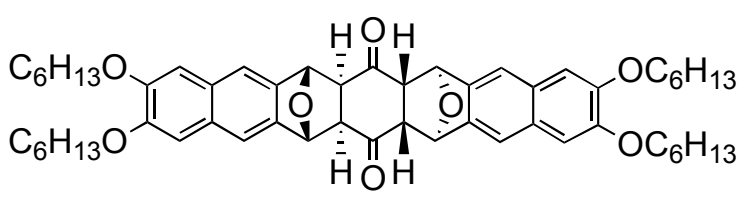

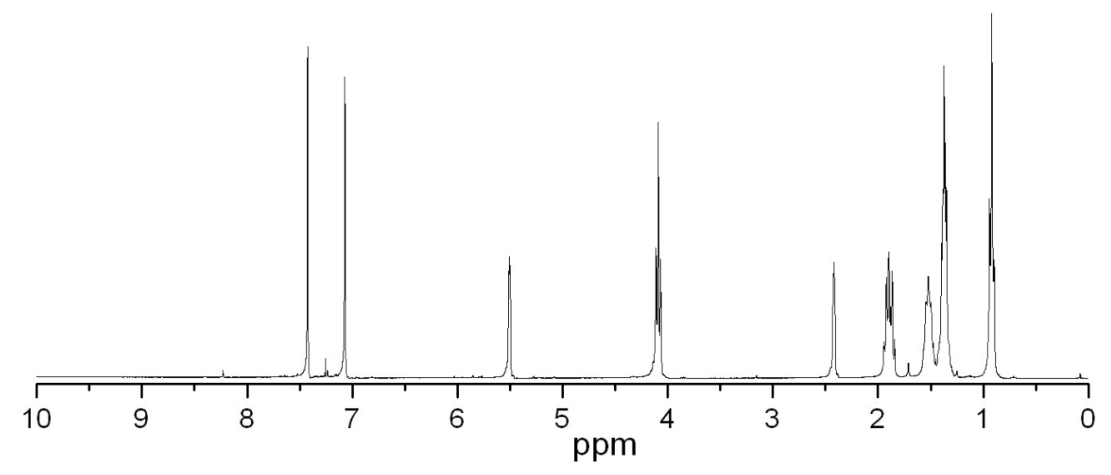

${ }^{13} \mathrm{C}$ Spectrum of $\mathbf{1 3}$ (exo/exo)
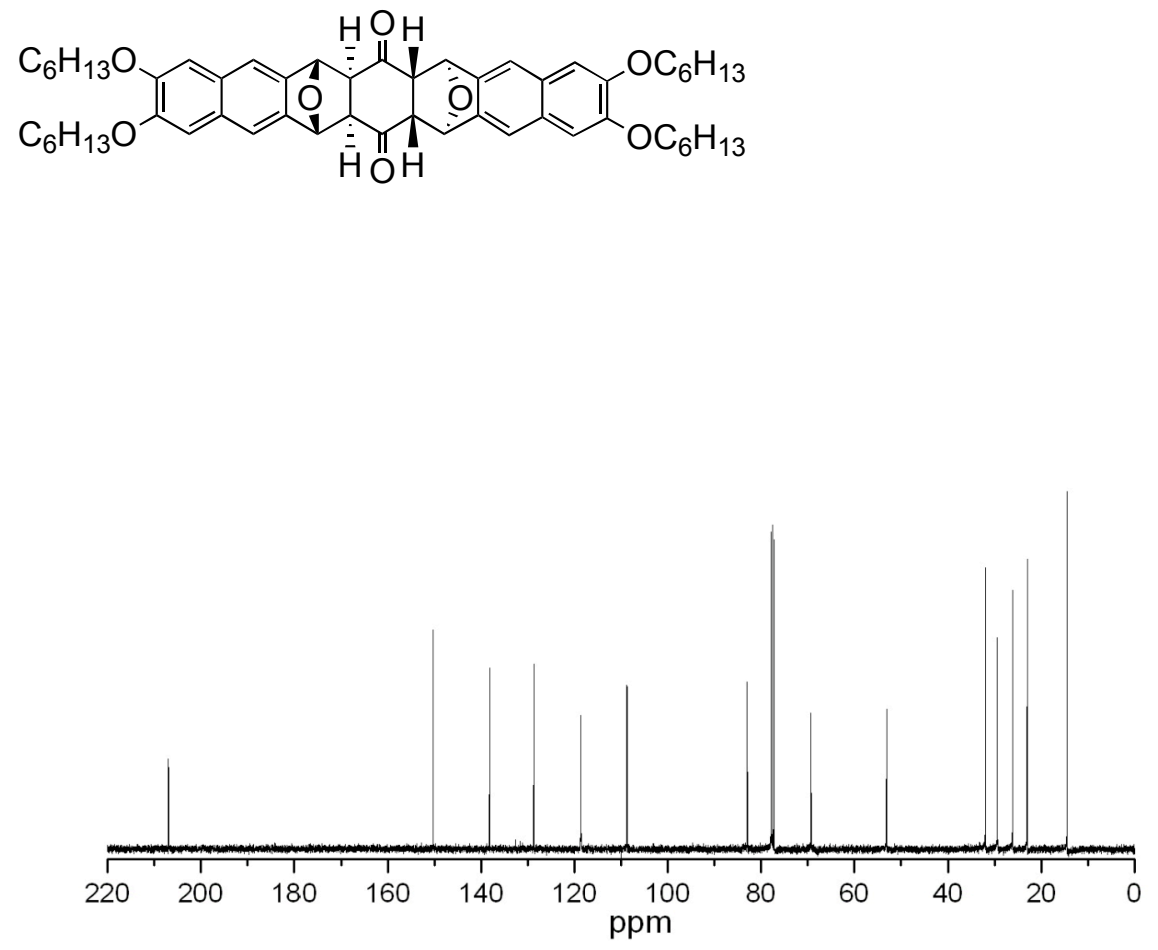
${ }^{1} \mathrm{H}$ Spectrum of $\mathbf{1 4}$<smiles>CCOc1cc2cc3cc4c(cc3cc2cc1OCC)-c1cc2cc3cc(OCC)c(OCC)cc3cc2cc1C4=O</smiles>

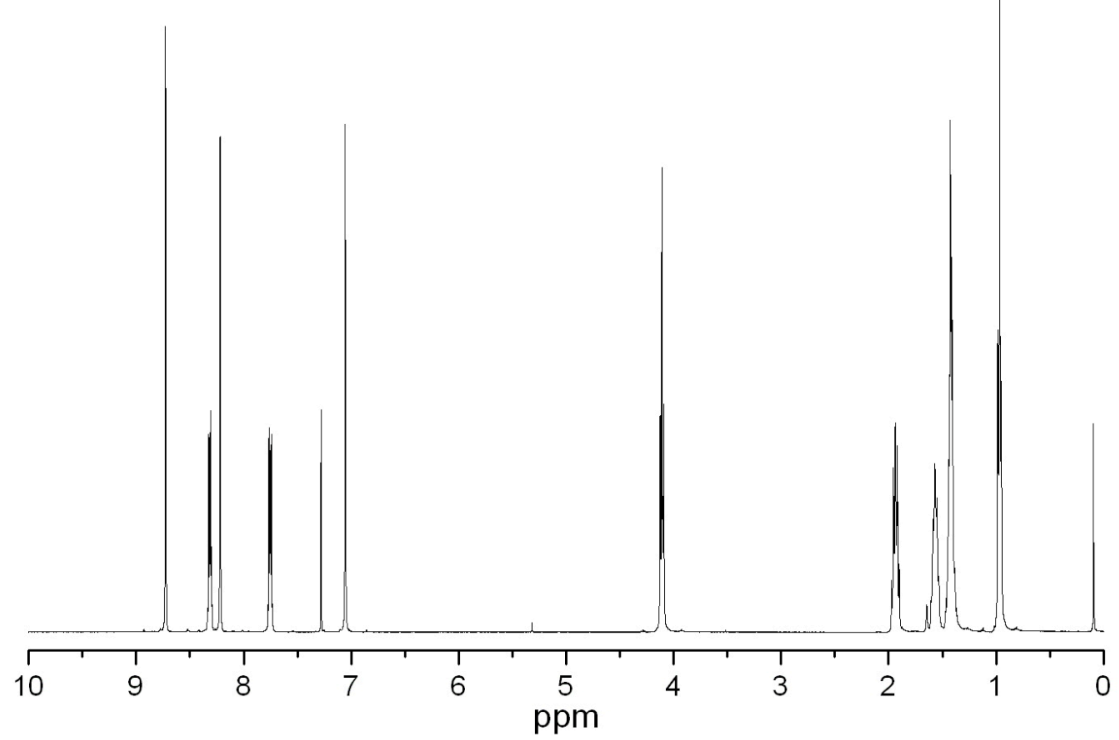

${ }^{13} \mathrm{C}$ Spectrum of $\mathbf{1 4}$<smiles>CCOc1cc2cc3cc4c(cc3cc2cc1OCC)-c1cc2cc3cc(OCC)c(OCC)cc3cc2cc1C4=O</smiles>

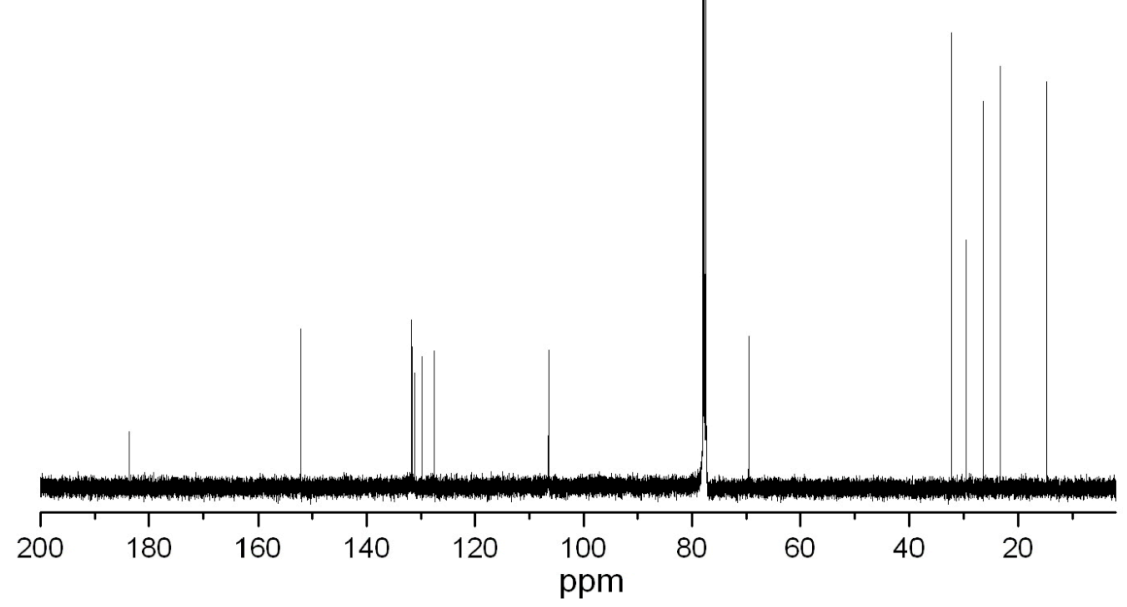

